\title{
A CASE FOR REIMAGINING SCHOOL LEADERSHIP DEVELOPMENT TO ENHANCE COLLECTIVE EFFICACY
}

A background paper for the Menzies Foundation

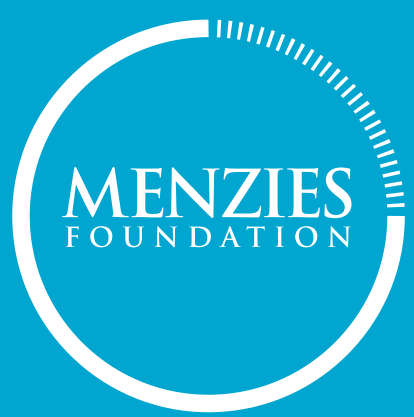


The Australian Council for Educational Research Ltd @ 2020

The Australian Council for Educational Research Ltd

19 Prospect Hill Road

Camberwell VIC 3124

Phone: (03) 92775555

ABN 19004398145

www.acer.org

ISBN 978-1-74286-592-8

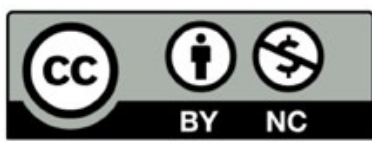

With the exception of any material protected by a trademark, and where otherwise noted, all material presented in this document is provided under a Creative Commons Attribution NonCommercial4.0 International Licence http://creativecommons.org/licenses/by-nc/4.0

\section{Recommended attribution}

A case for reimagining school leadership development to enhance collective efficacy by Kerry Elliott \& Hilary Hollingsworth. Published by the Australian Council for Educational Research for The Menzies Foundation.

Creative Commons Attribution NonCommercial 4.0 licence.

https://creativecommons.org/licenses/by-nc/4.0/

Available at: https://research.acer.edu.au/educational_leadership/5

\section{Recommended citation}

Elliott, K., \& Hollingsworth, H. (2020). A case for reimagining school leadership development to enhance collective efficacy. Camberwell, Australia: Australian Council for Educational Research. 


\section{Contents}

$\begin{array}{lr}\text { Contents } & 1\end{array}$

$\begin{array}{ll}\text { List of figures } & 3\end{array}$

$\begin{array}{ll}\text { Acknowledgements } & 4\end{array}$

$\begin{array}{lr}\text { Executive summary } & 5\end{array}$

Building a pipeline of talented school leaders............................................................... 5

An innovative 'Incubator' model .................................................................................. 5

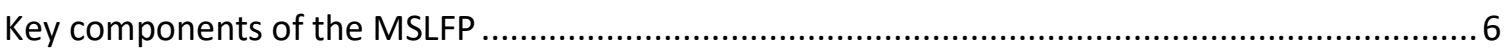

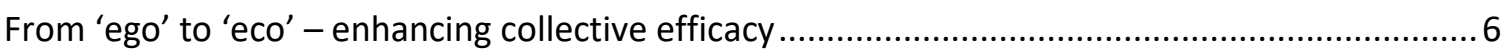

Evaluating collecting efficacy and developing insights................................................... 7

\begin{tabular}{l} 
Introduction \\
\hline
\end{tabular}

Part 1. The context of school leadership 9

1.1 Characteristics of effective school leadership 9

Instructional leadership practices are key to improving student outcomes...............................9

Leaders require a range of capabilities to manage adaptive and technical challenges ...............10

Effective leaders have a range of social, cognitive and affective skills ...................................11

1.2 Challenges facing school leaders 12

Leading in a volatile, uncertain, complex and ambiguous world .............................................. 12

Increasing compliance and workload demands ............................................................ 12

Constraints on the instructional leadership aspects of the role............................................. 12

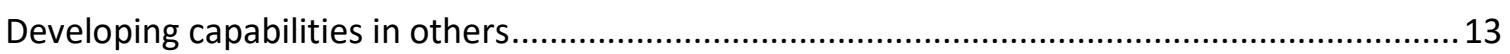

$\begin{array}{ll}1.3 \text { Challenges of education in Australia } & 14\end{array}$

Addressing the needs of diverse and contemporary learners............................................. 14

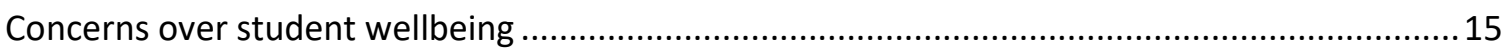

Public scrutiny of student performance ...................................................................... 16

Moving away from a traditional model of schools ............................................................... 16

$\begin{array}{ll}1.4 \text { A 'block in the leadership pipeline' } & 17\end{array}$

The current profile of school leadership ........................................................................ 17

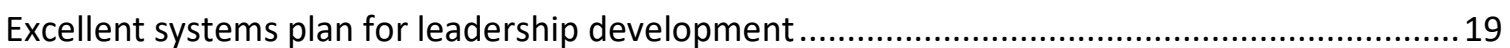

A systematic approach to leadership development is required.......................................... 19

Key features of effective leadership development ............................................................... 20

1.5 Questions framing the MSLFP 22

Part 2. The Menzies Foundation fellowship 23

2.1 Overview of the Menzies School Leader Fellowship Program 23

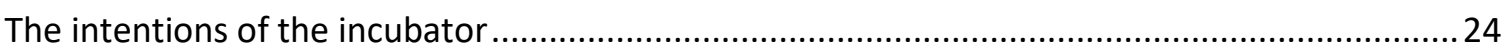

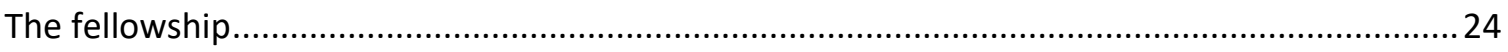

2.2 Distinguishing features of the MSLFP 25

Developing internal capabilities to manage complex challenges...........................................26

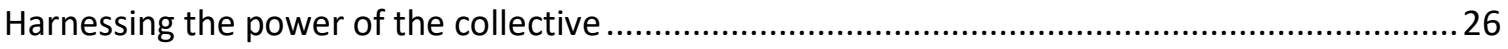

An incubator embedded in a collective efficacy strategy....................................................2 27

$\begin{array}{ll}2.3 \text { Defining collective efficacy } & 28\end{array}$

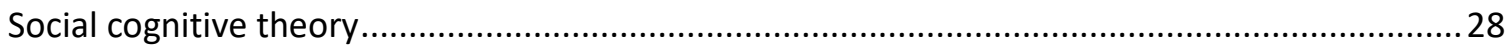




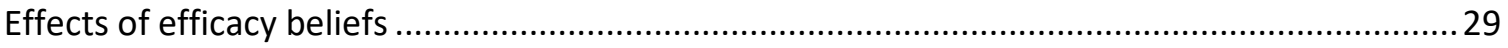

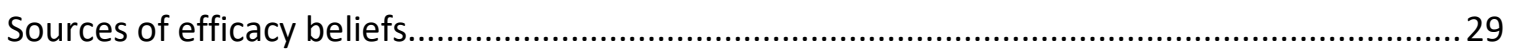

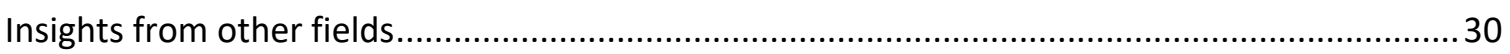

2.4 Collective efficacy in education 30

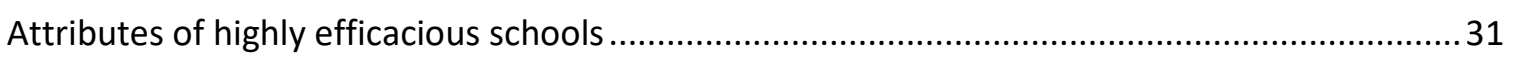

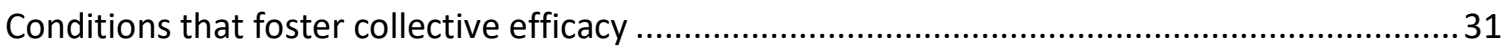

Collective efficacy beliefs support collaboration and teacher development................................32

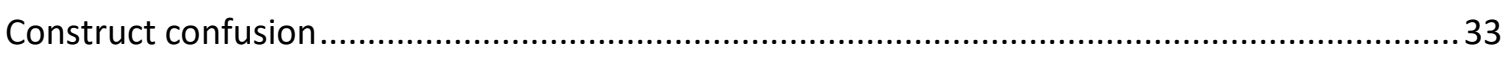

2.5 Collective efficacy as a leadership focus $\quad 34$

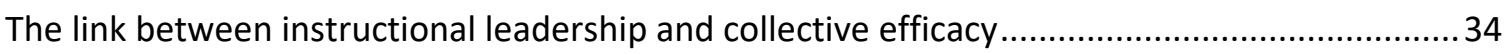

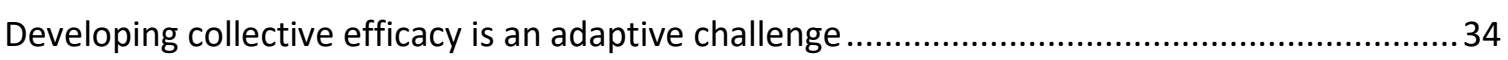

Collective efficacy emphasises the implicit and explicit conditions of system change ....................35

Educators with a strong sense of collective efficacy are more likely to persevere........................36

$\begin{array}{ll}2.6 \text { Areas where further research is warranted } & 37\end{array}$

2.7 Collective efficacy in the MSLFP

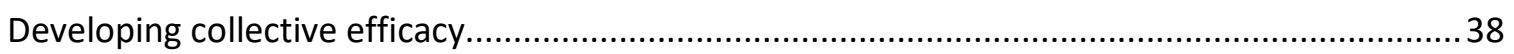

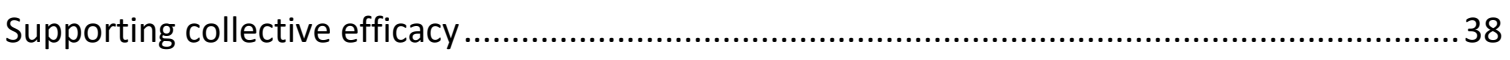

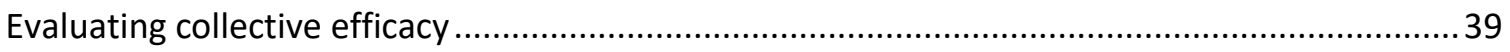

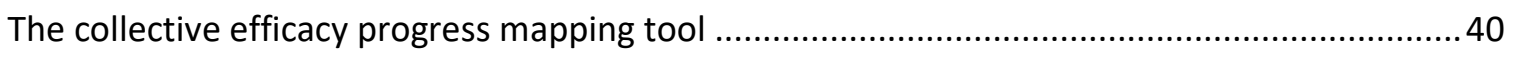

2.8 Conclusion and a future research agenda $\quad 41$

References $\quad 42$ 


\section{List of figures}

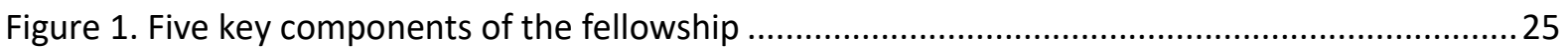

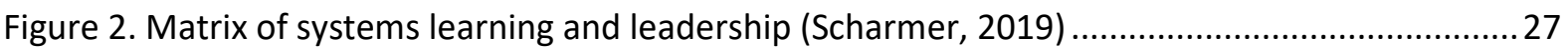

Figure 3. The triadic interplay in social cognitive theory (Bandura, 1986) .......................................29

Figure 4. Six enabling conditions for fostering collective efficacy (Donohoo, 2017a)..........................32

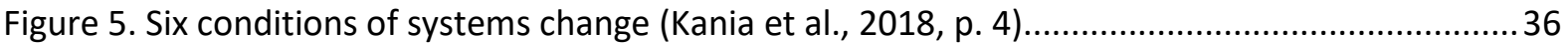

Figure 6. The MSLFP incubator focused on developing collective efficacy .......................................38

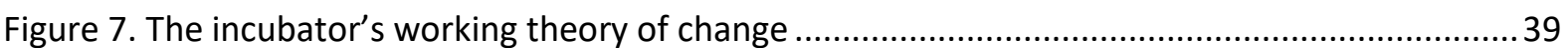




\section{Acknowledgements}

This paper was commissioned by the Menzies Foundation. Thank you to our colleagues at ACER for their contributions and careful editing. We would also like to acknowledge Clear Horizon, Angela Mina Consulting, EY and the Menzies School Fellows for their support and insights in developing this paper, and in particular the contributions of John Hattie, Katherine Henderson and Liz Gillies.

The views expressed in the paper are based on the input of various stakeholder groups but remain the responsibility of the authors. They do not necessarily represent the views of the Menzies Foundation or any one individual or organisation involved in the review. 


\section{Executive summary}

The work of school leaders is becoming more complex. Principals today face a range of challenges, including: an increasingly diverse student body; how best to prepare students for future employment and lifelong learning in a rapidly changing world; multiple compliance and workload demands; growing concerns over student wellbeing; and, increased public scrutiny of student performance.

We know from research that effective school leaders can drive improvements in teaching and learning, but they cannot do it alone. Collective efficacy is a key element of school improvement studies show it has a powerful influence on student achievement. Although school leaders can take action to nurture and improve collective efficacy among their teachers, it is not a simple task. This review suggests that while many school leadership programs exist, they are not equipping participants with the skills they need. Furthermore, very few target the leaders of tomorrow.

\section{Building a pipeline of talented school leaders}

In Australia, a high proportion of principals are in the over 50 age bracket, and fewer educators are aspiring to the role. It is clear that there is a blockage in the talent pipeline and an impending shortage of school leaders. Our findings suggest a more collective approach to leading the work of schools is required, and a more systematic effort to support and develop current and potential school leaders.

So, how might systems build a pipeline of individuals who are better prepared for the complexities of the role, and who can drive school improvement through collective efficacy, lifting student outcomes? Having an impact in the complicated, crowded space of school leadership, with multiple stakeholders and differing contexts and needs, is not easy.

Gaining a deeper understanding of what influences school leaders and what they need in the way of support and development is a crucial building block. Through taking a collaborative approach, working with existing school leaders on co-designed programs, we can gain valuable insights.

\section{An innovative 'Incubator' model}

With this in mind, the Menzies Foundation has developed an 'Incubator' model. The Menzies School Leader Fellowship Program (MSLFP) is a two-year, leadership development program that seeks to harness cross-sector expertise to understand how to build a pipeline of talented school leaders, equipping them with the knowledge and skills to successfully adapt to and take on the challenges and complexities of the role.

Unlike typical leadership development programs, the explicit focus is on increasing the skills and capability of leaders to build collective teacher efficacy. The MSLFP is not just about learning; it is about doing. The innovative Incubator model gives Fellows the opportunity to move from a traditional to an adaptive leadership approach, trialling strategies and interventions that are focused on enhancing collective efficacy within their own teaching teams. Funding, skills building, advice and research to create and learn from these interventions is provided by the Fellowship. 
The first cohort of five Fellows commenced the program in May 2019, with the second due to commence later this year. The aim is not to scale up the program, rather to build agency and a community of practice that supports existing school leaders to co-design solutions for their own context and student needs and to demonstrate a focus and model for future training of school leaders. These Incubator experiments will generate insights and examples that can feed into future research and practice, and be leveraged across the system.

\section{Key components of the MSLFP}

The MSLFP recognises that, in order to do the work necessary on self, school and system, leaders must have sufficient levels of management skills and social sensitivities. This is the starting point for development. The Fellowship consists of five key components:

- A diagnostic approach (assessments focussed on personality, decision making, resilience and wellbeing in the context of self, role and system);

- An accelerated planning day (supporting Fellows in explore and plan their journey, building on insights from the initial diagnostic assessments);

- Peer support groups (meeting six times over the two years, the group is a safe space for likeminded colleagues to support and challenge one another in their learning);

- Individual leadership coaching (eight sessions over two years, enabling leaders to unlock their potential and maximise their performance);

- Workshop modules (building iterative capability, three workshops will be delivered over the course of the program with the focus on developing collective leadership capabilities in relation to self, school and system).

\section{From 'ego' to 'eco' - enhancing collective efficacy}

Strategies and interventions trialled through the Incubator will vary from school to school, as each individual leader addresses teacher needs in their own context. However, the core focus of all this work will be developing collective efficacy. The MSLFP involves inspiring leaders to believe that their work with colleagues can make a difference to the learning lives of students. The program invites school leaders to explore their own leadership practice, what is needed in relation to their own context, the challenges they face in developing collective efficacy and the potential solutions.

The aim is to shift awareness from 'ego-system' to 'eco-system' by impacting a leader's ability to nurture deeper evaluative thinking about collective efficacy. Having a greater self-awareness, learning by listening, being able to build capacity in others, and learning by co-designing and implementing strategies collectively will develop Fellows' instructional leadership capability and lead to enhanced teacher collective efficacy and student outcomes. Importantly, delivering customised, needs-based projects in their own schools through the innovative Incubator model provides Fellows with a strong support network and learning 'sandpit' in which to practise their skills. 
At a school level, the Incubator's working theory of change is illustrated below:

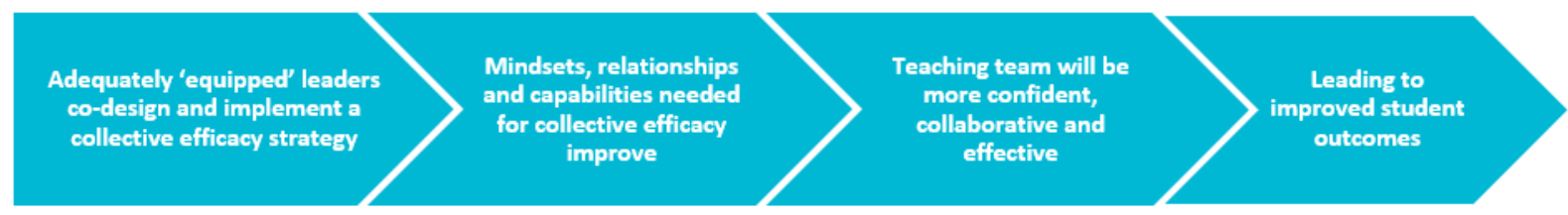

\section{Evaluating collecting efficacy and developing insights}

In keeping with the collective approach to driving school improvement and lifting student outcomes, developing learnings and insights from the Incubator is also very much a collaborative effort.

The Victorian Government's annual Staff Opinion Survey already provides a measurement of collective efficacy in schools, and this forms the basis of evaluation in the MSLFP. Informed by research, the Menzies Collective Efficacy Progress Mapping Tool has been developed for use by leaders and their teaching teams to assess, track and improve collective efficacy in their school.

Assessment is across four areas (school, leaders, teachers and students) and through four phases of maturity - from recognising the possibility for change through to achieving positive learning outcomes through a high sense of collective efficacy. Using the tool, school leaders and teaching teams can map the progress already made at a whole-school level, what they are working on now, and the next steps. The mapping tool will continue to be developed and refined during the Incubator process, and resources aligned to each of the four phases will be made available to support diagnosis, interventions, implementation and evaluation.

Some of the research and evaluation questions to be considered through the MSLFP include:

- What conditions are needed to improve the leadership of collective efficacy in schools? What practices and interventions enable these conditions to improve?

- How might we foster collective efficacy throughout the conceptualization, design, delivery, and assessment of change initiatives?

- What leadership styles and practices foster collective beliefs that leverage measurable impacts on student learning outcomes?

- What have we learned about the wider system affecting the pipeline of school leadership in Australia for developing collective efficacy? Does a focus and developing skills in collective efficacy more likely lead more to become leaders?

- What do we know about current school leaders and the capabilities that are required to build collective efficacy leadership within their schools? Based on the skill required, how might we better identify, support and accelerate the development of future school leaders?

It is hoped learnings and insights gained through the MSLFP will be useful for educators and systems leaders, informing practice, policy and new research and theory. 


\section{Introduction}

This paper draws together the research evidence and policy direction that underpin the Menzies School Leader Fellowship Program (MSLFP) and presents a case for reimagining school leadership development to enhance collective efficacy. The MSLFP is an incubator process that capitalises on individual, school, cohort and system-level leadership and aspires to develop scalable leadership interventions to improve student learning outcomes. The Fellowship is led by a multi-sector collaboration comprised of school leaders, their schools, and corporate, philanthropic and research partners. Together, the Fellowship aims to generate and scale learnings that will support school leaders to lead high-quality schools that provide the learning conditions and opportunities for students to be successful learners.

This paper is presented in two main parts. The first part outlines the context of school leadership. It begins with a review of the school leadership literature and what it tells us about the characteristics of effective school leaders, before focusing attention on the Australian context. Here, the challenges facing school leaders are identified and discussed as they work to meet the goals of education. There is evidence that the work of school leaders is becoming more complex, there are fewer educators aspiring to become school leaders, and a more collective approach to leading the work of schools is required. Consequently, there is a 'block in the leadership pipeline' which is having an impact on the development of leaders who are equipped to address current challenges. This section sets the scene for a case for reimagining school leadership development in Australia and concludes with a set of questions framing the MSLFP.

The second part focuses on the design of the MSLFP. It begins with an overview of the Fellowship, what it aims to achieve, and how it differs from other leadership development offerings and approaches. Collective (teacher) efficacy is introduced as an influential factor in schools and a key leadership strategy within the MSLFP. This section refers to the research on collective efficacy within and beyond education to better understand what it is, its significance in schools, and to determine what gaps might be present in the current literature. It is argued that while collective efficacy is a crucial aspect of school improvement, there is limited research on how it might be operationalised in schools and the type of school leadership that is required to operationalise it. This section describes the development, support and evaluation of collective efficacy within the MSLFP and concludes with research questions to be investigated as part of the Fellowship's program of research and evaluation. 


\section{Part 1. The context of school leadership}

This section focuses on what is known about school leadership in the current educational context. There is extensive research on school leaders confirming that effective education systems have effective leaders. Although there is a lot known about what it takes to lead an effective school, the current context reflects a range of challenges facing school leaders and a need to reimagine leadership development.

\subsection{Characteristics of effective school leadership}

School leaders have long been acknowledged as playing a critical role in sustaining the learning environment and supporting and fostering the conditions under which quality teaching and learning take place (Day, 2017; Robinson, Hohepa \& Lloyd, 2009; Robinson, Lloyd \& Rowe, 2008;). Research confirms successful schools are led by effective school leaders who create and sustain cultures of high expectations, and conditions that support teachers to build their capacities and abilities (Barber \& Moushed, 2007; Day, 2017; Dinham, 2007; Lui \& Hallinger, 2018; Robinson et al., 2008).

Effective school leaders create opportunities for rigorous professional learning and collaboration that promotes a culture conducive to learning and development (Elliott, 2019; Leithwood, Harris \& Hopkins, 2020; Robinson et al., 2007). In practice, effective school leadership involves:

- Establishing goals and expectations and engaging staff and others in the process.

- Strategic allocation of resources to make teaching goals a priority.

- Planning, coordinating and evaluating teaching and the curriculum.

- Promoting and participating in both formal and informal teacher learning and development.

- Ensuring an orderly and supportive environment to protect time for teaching and learning (Robinson et al., 2007).

School leaders who focus on teaching and learning have a significant influence on the quality of teaching in schools, and can significantly impact student achievement and wellbeing outcomes.

\section{Instructional leadership practices are key to improving student outcomes}

Instructional leadership practices are crucial to improving student outcomes, and consequently, education systems throughout the world have acknowledged that instructional leadership should be core to the role of school leaders (Dinham, 2013; Hallinger \& Heck, 1998; Hallinger \& Wang, 2015). The renewed interest in instructional leadership is grounded in research that has validated its effects on student learning, school quality, and school improvement (Hallinger, 2011; Leithwood, Patten \& Jantzi, 2010; Robinson et al., 2008). These findings are further supported in Hattie's (2009) extensive meta-analyses:

school leaders who focus on students' achievement and instructional strategies are the most effective... It is leaders who place more attention on teaching and focused achievement domains ... who have the higher effects (p. 83). 
Specifically, instructional leaders have an in-depth knowledge of learning and teaching strategies and approaches to facilitate this; they use evidence to evaluate and improve school practice and ensure the core business is to facilitate teaching and learning. They focus their efforts on boosting student results, they stay knowledgeable about evidence-based teaching, learning and assessment, they hold high expectations of educators in the school, they supervise their teachers, and they support quality professional development (Hattie, 2015).

\section{Leaders require a range of capabilities to manage adaptive and technical challenges}

Leading improvement is a challenging task and requires leaders who can manage adaptive and technical challenges. Heifetz and Linksy (2002) noted that technical challenges often have some good or best practice solutions which, if appropriately implemented, will solve the problem. For example, technical challenges (e.g., developing a course website) can be addressed by increasing our knowledge, skills and expertise, or by hiring an expert to assist in solving them (Drago-Severson, 2009; Kegan \& Lahey, 2000). People are therefore generally receptive to technical solutions because they make sense and people have confidence that they will succeed. Typically, these challenges involve a change to a part of a school, organisation or system, rather than to people's belief systems or the way they work, which affect all parts of a school.

On the other hand, the kinds of adaptive challenges faced in education (e.g. implementing a new policy, etc.) are more difficult to solve (Drago-Severson, 2016). To illustrate, Heifetz and Linksy (2004) use the example of the mechanic who can fix our car's brake linings, but who cannot stop our 80 -year-old father from riding the brake pedal because he's afraid of driving too fast. DragoSeverson and Blum-DeStefano (2018) explain that:

The root causes of adaptive challenges are hard to pin down or identify. In fact, they don't come with ready-made answers (even from experts), and we need to live with and in these kinds of challenges as we are all figuring them out (p. 5).

The key difference between the two is that the knowledge required for addressing technical problems is currently available while solving adaptive challenges involves people working to find solutions. Adaptive challenges require leaders in all contexts to learn and grow as they work on such problems and address the tremendous amounts of complexity and ambiguity inherent in them. Understanding the distinction between the two is foundational to problem-solving and effective leadership.

Robinson (2017) explains that school leaders need to use relevant knowledge for solving complex educational problems while building relationships of trust with those involved to solve them. Leaders need to be able to reconsider their views and to do so as "not a matter of mere perfunctory listening to contrary opinions but a genuine readiness to revise or even abandon one's views in light of new objections or counter-evidence" (Spiegel, 2012, p. 28). This requires leaders to develop their cognitive and affective capacities so that they can manage change and in doing so, decipher problems quickly and create conditions to build capacity (Drago-Severson \& Maslin-Ostrowski, 2018). 


\section{Effective leaders have a range of social, cognitive and affective skills}

Effective leaders have a range of social, cognitive and affective skills however some authors suggest there is a growing gap between the complexity of the workplace and the capabilities of its leaders (Lahl \& Egan, 2012). Robinson (2017) insists that leadership today requires 'using knowledge', rather than 'having knowledge' and school leaders are needed who use that knowledge to inform their educational decision-making. Despite this, there is very little research that has directly investigated the relationship between leadership cognition and behaviour (Mumford, Watts \& Partlow, 2015) and how different levels of capability affect leadership performance and student outcomes (Robinson, 2017).

School leadership is multi-faceted and includes a focus on instructional and management skills; however, there are other capabilities required to be an effective leader. Bennis and Thomas' (2002) research led them to conclude that what makes a leader more effective has something to do with the different ways they lead people to deal with challenges and opportunities. They found that while leaders may be respected for 'what they know' and 'what they do', they more often than not were recognised for 'who they are' and it is very often the strength of internal personal resources that define leaders and suit them to the role in the first place (Bennis \& Thomas, 2002).

High-performing leaders consistently demonstrate sophisticated personal and interpersonal qualities. These include self-awareness and personal wellbeing, self-management (including emotional intelligence, empathy and resilience), social awareness and relationship management (AITSL, 2017). Scholars and practitioners agree that managing adaptive challenges, and their inherent tensions are crucial tasks of leadership in our contemporary world (Drago-Severson \& Blum-DeStefano, 2016; Kegan \& Lahey, 2016), and that personal and interpersonal qualities are becoming increasingly important (Drago-Severson \& Maslin-Ostrowski, 2018).

Leithwood, Harris and Hopkins (2008) found from their review of the scholarly literature only modest amounts of research about the traits of effective school leaders. They concluded that there was no definitive list of school leadership capabilities or attributes supported by the broader leadership research community. In Leithwood et al.'s (2020) revisit of the literature, they found a small number of recent studies that led them to suggest that there are several personal traits that may explain a high proportion of the variation in leadership effectiveness. They noted that, at least under challenging conditions, there was evidence to suggest that the most successful school leaders are open-minded and ready to learn from others. They are also flexible rather than dogmatic in their thinking within a system of core values, persistent (for example in pursuit of high expectations of staff motivation, commitment, learning and achievement for all), resilient and optimistic (Leithwood et al., 2020).

Leithwood et al. (2020) furthermore suggested that "while further research is required, a welldefined set of cognitive, social and psychological 'personal leadership resources' show promise of explaining a high proportion of variation in the practices enacted by school leaders" (p. 15). These skills are outlined in The Ontario Leadership Framework (2013) which identifies three personal leadership resources (PLRs) - social, psychological and cognitive skills that are crucial capabilities required of school leaders for them to carry out their role effectively. 


\subsection{Challenges facing school leaders}

There is a range of challenges facing leaders in the current environment. The increasing demands of our contemporary world call for leaders with exceptional internal capabilities to create conditions of authentic and meaningful learning and development within their schools and beyond (DragoSeverson \& Maslin-Ostrowski, 2018). Leithwood et al. (2020) explained that the central task for leaders in schools is to help improve teaching and learning and "such performance is a function of employees' beliefs, values, motivations, skills and knowledge and the conditions in which they work" (p. 7). They suggested that successful school leaders, therefore, should include practices helpful in addressing each of these "inner and observable dimensions of performance - particularly in relation to teachers, whose performance is central to what pupils learn" (Leithwood et al., 2020, p. 7).

\section{Leading in a volatile, uncertain, complex and ambiguous world}

Leading in a volatile, uncertain, complex and ambiguous (VUCA) world is challenging. To illustrate, Scharmer (2018) notes that technological, environmental and social disruptions have fuelled increasing levels of burnout and depression, unprecedented ecological destruction and higher levels of inequality and fragmentation in modern society. Scharmer (2019) suggests that overcoming these challenges calls for "people who are agile and co-creative and who can make their organisations thrive in a world of volatility, uncertainty, complexity and ambiguity" (p. 4). This idea is supported by Heifetz and Dorffer (2018), who suggest leaders are challenged to achieve new levels of adaptability and new capacities. In the education sector, these new expectations of leadership are considered to include:

becoming ever more responsive to the complex challenges presented by an increasingly diverse student body ... as the world 'outside' of education changes, so must the world 'inside' of education with much of the responsibility for leading the changes resting with school leaders (Timperley et al., 2020, p. 1).

\section{Increasing compliance and workload demands}

School leaders face enormous challenges as they respond to and translate a 'relentless barrage' of policies and mandates for which they are accountable (Bryk, Gomez, Grunow \& LeMahahieu, 2015; Drago-Severson \& Maslin-Ostrowski, 2018; Kegan \& Lahey, 2016). They must manage multiple demands from within the school, the broader community and the central and regional education offices, often spanning many legal requirements, as well as government policy and program commitments (Duignan, 2020; Schleicher, 2016, 2018). Hence, increased compliance and continual change to these requirements, have added to the workload of the expected role of the principal (Dinham, Elliott, Rennie \& Stokes, 2019).

\section{Constraints on the instructional leadership aspects of the role}

The growing demands placed on schools has placed constraints on leaders to fulfil the instructional leadership as well as managerial aspects of the role. School leaders are not only educational leaders; they also play the role of being workplace managers, looking after the day-to-day operational aspects of running a safe and productive school environment. In many instances, principals are also 
regarded as leaders within the local community. They have to attend to the pressures of life outside of work such as family commitments, financial obligations, personal matters and health issues. The ability to manage multiple demands within the school requires a blend of technical and leadership skills, resilience and resourcefulness to help them navigate a complex environment (Riley, 2019; Victorian DET, 2018).

Although the priority of policymakers worldwide has been to focus on instructional leadership practices, scholars have highlighted limitations in the time, confidence and capacity of many principals to fulfil this role (Hallinger \& Murphy, 2012; Marshall, 1996). Findings have highlighted that principals who either failed to see instructional leadership as a key part of their role or who lacked confidence in this area were less likely to engage in this type of leadership proactively (Dimmock \& Hattie, 1996; Leithwood \& Jantzi, 2008; Lucas, 2003; Miller, 2015).

More often than not, the management of the school has taken precedence. The increasing demands and compliance placed on school leaders coupled with little time to manage these aspects of the role have likely influenced a leader's time, confidence and capacity to function as effective instructional leaders (NSW, 2017; Thomson \& Hillman, 2019). National surveys have reflected school leaders' concerns about the enormity of their role. An NSW survey (2017) reported principals spent only 30 per cent of their time on leading learning and teaching, 40 per cent on management of the school and six per cent on leading improvement, innovation and change. They reported that they felt isolated, and unprepared for the leadership and management aspects of the role when transitioning into the role (NSW, 2017). In another study, over one-third of principals surveyed reported that they had had no principal or instructional leadership training. Of those who had received training, 45 per cent said that it was 'average' to 'weak' in supporting the development of their capabilities (Freeman, O’Malley \& Eveleigh, 2014).

The results of the OECD's 2018 Teaching and Learning International Survey (TALIS) highlighted that, compared to other OECD countries, Australian school principals undertook less formal training in instructional leadership before they commenced their role as principal. "This result suggests that the majority of school leaders in Australia have not received training specific to their role as a principal prior to taking up their positions" (Thomson \& Hillman, 2019, p. 98). This highlights that there is room for improvement in the preparation and training of school leaders.

Interestingly, some evidence suggests that supporting leaders so that they can be instructional leaders and cope with managerial pressures may help them to feel more confident in their role. Consequently, principals who feel more 'in control of their time' may also feel more confident in their ability to accomplish the challenging task of leading learning (Grissom et al., 2012; Hallinger \& Murphy, 2012; Horng, Klasik \& Loeb, 2010; Leithwood \& Jantzi, 2008; Miller, 2015; Versland, 2009).

\section{Developing capabilities in others}

In a world facing increased innovation and complexity, the need to work together, to be creative, and to build leadership capabilities in others is paramount. Heifetz (1994) argued that solutions to adaptive challenges reside not in an individual, but in the collective wisdom of employees at all levels. He explained that organisations need to use one another as resources, often across boundaries, and learn their way to those solutions (Heifetz, 1994). 
Likewise, Duignan (2012) claimed that "leaders cannot do it all by themselves. They have to work with and through others to achieve their organisation's vision and goals" (p. 54). As a result, the importance of developing the capabilities of others has been recognised and increasingly cited in the literature, and there is an emphasis on the distribution of leadership and the promotion of middle leaders (e.g. Daggett, 2014; Dinham et al., 2018; Edwards-Groves, 2018; Hargreaves et al., 2018). Leaders need to work "more collegially with key colleagues and stakeholders and use their gifts and talents to promote, support and sustain collective approaches to improving the teaching and learning landscapes in their schools" (Duignan, 2020, p. 65). Today's challenges require "solutions that reach beyond one individual. Rather than looking at individuals to solve problems, people increasingly recognise that effective solutions come from networks and other collaborations" (Jensen et al., 2017, p. 20).

Building capacity for collaboration and ongoing learning and development might be key to the sustainability and wellbeing of leaders, teachers, schools and the broader education system (DragoSeverson \& Blum-DeStefano, 2018). However, Duignan (2020) cautions that:

achieving sustainable collective leadership capacity in complex systems and schools, involves a re-visioning of the educational architectures of schools - that is, the structures, process, time and space - for delivering education to students in an uncertain and rapidly changing world (p. 65).

\subsection{Challenges of education in Australia}

Enhancing student achievement and providing each student with a quality educational experience has long been the most important outcome of education systems (Elliott, 2015). Achieving an education system which promotes excellence and equity, and aims to be fair, equitable and topperforming, are some of the core goals of education in Australia. However, there are several challenges facing school education if it is to meet the goals of the Alice Springs (Mparntwe) Education Declaration (2019). These challenges include meeting the needs of an increasingly diverse student population and addressing issues of student wellbeing and declining student outcomes. A brief description of these challenges are provided because each has implications for leaders who are required to address these challenges in their schools.

\section{Addressing the needs of diverse and contemporary learners}

An emphasis on addressing the needs of all learners to ensure they develop the full set of cognitive and socio-emotional skills they are capable of and are prepared for future work, life and study have taken a prominent position in policy reform (Gomendio, 2017). The Review to Achieve Educational Excellence in Australian Schools, commonly referred to as Gonski 2.0 (DET, 2018), claimed that education should be "tailored to individual learning needs, and relevant to a fast-changing world" (p.viii).

Consequently, schools are faced with increasing challenges to support the needs of a diverse population. This includes those in rural or remote locations, students with disability, Aboriginal and Torres Strait Islander students, students from non-English speaking backgrounds, students from low 
socio-economic backgrounds, gifted and talented students, academically advanced or less-advanced students, or any combination of these. According to Masters (2019):

the size and diversity of today's student population mean that students come to school with very different backgrounds, starting points and learning. The principles of equity and inclusivity require that every student be given access to the same curriculum and the support they require to progress and succeed ( $p .5)$.

In conjunction with meeting the cognitive and social needs of diverse learners, schools are also to promote learners who "are creative, innovative and resourceful and are able to solve problems in ways that draw upon a range of learning areas and disciplines" (DET, 2018, p. 6).

Rapid advancements in society have required workers to adapt and keep up with advanced skill development as low-level activities have been computerised or outsourced to low wage economies (Masters, 2019). These changes have left educational settings faced with the challenges of how to prepare students for future employment possibilities adequately. For, "basic levels of knowledge and skill will not be sufficient to negotiate, and function in this more complex world [and] schools will need to lift education standards across the board" (Masters, 2019, p.14).

Schools need to ensure that students acquire the high-level skills which are in increasing demand in the workplace and the knowledge, understanding, skills and capacities to navigate their way in an increasingly complex world. Schools have been asked to address general capabilities and crosscurriculum priorities. These include developing the skills required for the $21^{\text {st }}$-century workplace (World Economic Forum, 2016; Foundation for Young Australians, 2018) and needed for lifelong learning (Lucas \& Smith, 2018), with the four most common skills being creativity, communication, problem-solving and critical thinking (Care et al., 2017).

With demand on teachers to differentiate and adopt inclusive practices that "remove barriers to learning by considering students' capabilities and taking into account their learning needs" (Graham, Berman \& Bellert, 2015, p. 2) a focus on individual growth requires a shift in teaching and learning to support all students. This has implications for school leaders who are required to develop conditions in their schools that foster continual professional learning to support the demands and changing requirements of teaching and learning.

\section{Concerns over student wellbeing}

Despite better access to services and significant improvements to the quality of life in recent years, levels of stress, anxiety and depression are on the rise (OECD, 2018; Mogato, 2019). There is increasing concern over student physical, social, mental and emotional wellbeing with more adolescents reporting mental health problems and dissatisfaction with their lives. Mental health problems are among the most common disabling health conditions in young people (Gillard, 2019). Schools are increasingly concerned not only with students' academic performance but also with students' wellbeing. School leaders have been required to review and refine policies to reflect the Child Safe Standards. The work of school leaders also includes a key role in building a positive learning environment where the whole school community feels included, connected, safe and respected (see the Australian Student Wellbeing Framework, 2018). 


\section{Public scrutiny of student performance}

National and international reporting has placed intense scrutiny on school performances, and social issues have put pressure on schools to attend both to the academic 'basics' and to deal with the 'extras'. Additionally, declining student outcomes against international measures have exacerbated the challenges facing schools. Although there is evidence, based on NAPLAN tests conducted between 2008 and 2018, that basic literacy and numeracy skills have improved, these results demonstrate declines in student performance in the middle years (after Year 5), particularly in reading and writing (Ainley \& Gebhart, 2015; Goss, 2019). Internationally, the Programme for International Student Assessments (PISA) conducted between 2000 and 2015 show a significantly longer-term and continuing decline of 15-year-olds' understandings of how to apply basic reading, mathematical and scientific knowledge and skills to practical problems. Furthermore, there is evidence that the gaps in literacy and numeracy levels have not closed for any major equity groups and that some schools and students are delivering lower rates of learning growth than comparable schools/students where students have similar backgrounds and starting scores (Thomson, DeBortoli, Underwood \& Schmid, 2019).

Academic performance has continued to decline when compared to other Organisation for Economic Co-operation and Development (OECD) countries. As reported by Gonski 2.0 (DET, 2018), "Australian students and schools are not improving at the same rate and are falling short of achieving the full learning potential of which they are capable" (p. viii). According to the most recent PISA results, Australia's mean performance has decreased in reading, mathematical and scientific literacy and changed over the PISA cycle. For example, in reading literacy, "while in their first PISA cycle, four countries (Canada, Hong Kong (China), Ireland and Korea) performed at the same level as Australia, and three countries (Estonia, Macao (China) and Poland) performed at a level lower than Australia. In PISA 2018, all seven of these countries performed at a higher level than Australia" (Thomson et al. 2019, p. xv).

\section{Moving away from a traditional model of schools}

Wilson (2018) argues that meeting the needs of contemporary learners requires moving away from a traditional model of schools which entails a cultural shift away from a narrow management model. Wilson (2018) notes that if schools wish to support "more creativity, collaboration, and appetite for risk in schools, then the organisational structures, systems, and processes must change and change significantly" (p. 31). Moving away from a traditional model of schools presents challenges for leaders when a catalyst for improving is developing collective teacher efficacy. For if schools want students to be more collaborative, creative and self-directed learners "the system (or organisation) in which this work happens must reflect a collaborative, creative, autonomous culture" (Wilson, 2018, p. 32).

According to Duignan (2020), "many system and school leaders are struggling to respond positively and creatively to these challenges, partly because adaptation involves new learning and the development of capacities that prepare us for unfamiliar circumstances and environments" (p. 45). These challenges have an impact on policies and practices in educational systems and schools, and include: 
- An increasing evidence base for the positive power of efficacy of collective professional commitment and action in schools.

- Increasing the use of interactive technologies that enable connectivity of people like never before.

- Pressures for a pedagogical paradigm shift, including mindset changes, to respond to these new technological capabilities, as well as the changing learning needs of contemporary and future students.

- Evidence on emerging architectural disruptions in education which will require structural and pedagogical reform in system and school policies and practices, including leadership responses (Duignan, 2020, p. 45).

\subsection{A 'block in the leadership pipeline'}

There is a lot of research on effective school leadership. However, this review suggests there are many challenges facing school leaders, and there is, therefore, a need to understand better the types of leadership that might be required to meet these challenges. Creating a diverse and extensive pool of people interested in all levels of school leadership is integral to growing leadership capacity across a jurisdiction or school. It involves moving away from focusing on individuals as 'hero' leaders, towards fostering collective and collaborative leadership capacity. This approach strengthens leadership and ensures those with aspirations to lead in the future are supported to set targeted development goals and supported to develop professionally from early in their careers (AITSL, 2017). However, the current profile of school leadership in Australia is aging, and the challenges faced by the increasing complexity of the role suggests there is a block in the leadership pipeline. This section proposes that a new approach to leadership development is required that identifies, supports and cultivates future and current school leaders.

\section{The current profile of school leadership}

There are significant and impending issues facing the current and future profile of school leadership in Australia and a growing recognition that the challenges the system faces cannot be solved alone. Recent policy attention to leadership recruitment, support and development in Australia reflects the growing interest in this area. This interest is a result of the impending shortage of leaders willing to take on the principal role, with several studies suggesting many school leaders are struggling with the demands of the job (AITSL, 2017; DET, 2018; Riley, 2019).

\section{Issues related to workload and personal wellbeing}

The Principal Workload and Time Use Study (NSW, 2017) reported that the decision-making culture of schools needed to change to help principals manage their workloads. The study found that there was a lack of trust between principals and the department. Principals reported that they generally did not believe the department acted in their best interest or had their back if things went wrong. Some principals said that they felt 'lonely' in their role and often felt isolated from and unsupported by the department. Principals were risk-averse and often adopted a compliance-based mindset when making decisions; seeking comfort in the 'norm' or 'standard'. 
The last decade has seen increasing demands on schools, amid continual policy reforms and curriculum mandates. The need for continual learning and to be resilient in the face of increased scrutiny has placed extra demands on educators which have no doubt impacted on their wellbeing. Globally there are concerns about teacher and school leader supply for a stable and productive workforce (McCallum et al., 2017). Stress and emotional exhaustion levels in classrooms are at a high, as educators grapple with growing workloads and challenging behaviour from students and parents (Gillard, 2019). These challenges in the last decade have had significant consequences on the broader education system, with wellbeing found to be impacting on resilience and self-efficacy, social-emotional competence/emotional intelligence and personal responses to educators' work: burnout, fatigue, exhaustion and stress (McCallum et al., 2017). These studies have cited educators are struggling with unmanageable workloads, feeling less confident that they could handle the workload and with increasing levels of burnout. Burnout named an occupation phenomenon by the World Health Organization (WHO, 2019) has significant implications for the wellbeing of the broader workforce, with a recent WHO study suggesting that depression and anxiety were costing the global economy US \$1 trillion each year in lost productivity.

Dinham et al.'s (2018) study reported that although those in the principal role enjoyed it and could not think of a more important role, many acknowledged feelings of stress, long work hours and found the 'EQ stuff' the most challenging. Concerns over wellbeing have been well cited in the literature and are of growing interest and policy focus. When compared to other professions, principals have reported experiencing higher levels of job, emotional and cognitive demands and greater levels of stress (Riley, 2019). There is increasing research to suggest that wellbeing, efficacy, and confidence are integral to learning (Cahill et al., 2014; O'Connor et al., 2019). Therefore, it can be argued that if wellbeing is important to learning and educators need to be lifelong learners, then understanding the connection between wellbeing and being an effective educator, and how it relates to student wellbeing is paramount (Schleicher, 2018).

There is research indicating that positive mental health and emotional wellbeing are closely related to the development of psychological and emotional resilience. Oades (2018) theory of wellbeing, 'thrivability theory', highlights wellbeing as feeling connected, capable and content. Therefore, if wellbeing is about feeling connected, capable and content, then having the agency of wellbeing and the psychological state to meet the increasing levels of complexity in the workplace is essential.

\section{Supply and demand issues}

In Australia, fewer educators are aspiring to the role. With an increasing number of aging principals and less wanting to take on the role, "Australia needs urgently to expand the pool of future school leaders as there is a looming shortage due to retirement" (DET, 2018, p. 94). There is a scarcity of applicants to fill available school leadership positions, with less wanting to take on the extra responsibilities of the role for the minimal pay increase. Developing a strong pool of highperforming, passionate school leaders who can exercise the structural autonomy they are provided with is critical to lifting Australian student outcomes (DET, 2018). 


\section{Excellent systems plan for leadership development}

Excellent school systems carefully plan for and develop their school leadership workforce and make an extensive investment in school leadership development programs.

When it comes to whole-system improvement, some argue that improving the quality of school leadership is a higher strategic priority than improving the quality of individual teachers, due to a principal's influence across a school (Jensen, Downing \& Clark, 2017, p.1).

Investing in a leader's capacity to lead improvement should be seen as an end-to-end pipeline solution. As Munby (2019) noted:

I am not aware of any high-performing school system, or one that is rapidly improving, that leaves leadership development to chance. It is too big a risk for the future (p. 20).

No high performing systems rely solely on leadership development to prepare great school leaders, and the literature varies about the most effective features of leadership development. However, Jensen et al. (2017) noted in their study of high-performing school systems that leadership development should focus on action learning. Key components of effective action learning-oriented leadership development include:

- A problem, challenge or task;

- A group of four to eight people;

- A questioning and reflective process;

- Development of strategies and action plans;

- A commitment to three levels of learning (personal, group and organizational); and

- A coach, facilitator or advisor.

Jensen et al. (2017) furthermore found that effective leadership development provided time for leaders to implement what they were learning and time for leaders to connect with key colleagues and stakeholders with whom they shared leadership and decision-making processes. According to Jensen et al. (2016) connection of the learning to a leader's context ensured "problems of relevance and applicability" and an opportunity for reflection, experiential learning or the ability to practice the new ideas and behaviours (p. 17).

\section{A systematic approach to leadership development is required}

Despite urgent needs for a systematic approach to leadership development, researchers have identified a longstanding gap in leaders' preparation and knowledge about how to support authentic adult learning and development (Elmore, 2007; Kegan \& Lahey, 2016; Shoho, Barnett, \& Tooms, 2010). Over the past ten years, there has been significant investment in building leadership capability through a range of initiatives. For example, school leadership frameworks such as the Australian Professional Standard for Principals (AITSL, 2011) have been developed outlining what an effective principal or school leader should know, understand and do. However, the potential problem is that standards themselves can be limited to becoming a series of boxes to be ticked and may lack the identification of critical factors, including personality traits and leadership capabilities, required from school leaders to enhance collective teacher efficacy. 
Experience as a teacher does not necessarily mean that leaders have developed the required knowledge, skills and abilities needed to lead learning and teaching in a school. Thus, the need to define, identify and develop school leaders has been acknowledged (Jensen et al., 2015). Although there are many educational leadership programs offered in Australia, those focused solely on developing and preparing aspiring leaders for the principalship are less common. Each of the government, Catholic and independent systems and sectors has its approach to principal preparation. While few offer a program or activity designed explicitly for preparing principals, many have strategies that target leadership development as part of more generalised leadership programs.

An environmental scan conducted by AITSL in 2015 identified a total of ten dedicated principal preparation programs in Australia. According to the scan, these programs had only a small reach, many were ad hoc, and they did not represent a coordinated nor strategic approach to the ongoing, systematic and effective preparation of school leaders for our nation (AITSL, 2015). The following recommendations for improving principal preparation in Australia were noted:

- Take a systematic, standards-based and coherent approach.

- Identify and nurture talent.

- Match learning to an individual's capabilities, career stage and context.

- Use evidence-based adult learning techniques.

- Evaluate programs for impact (AITSL, 2015).

Furthermore, Gonski 2.0 (DET, 2018) reported that Australian school systems and schools need to adopt a more proactive approach to leadership talent development and offer a distinct and structured pathway to becoming a principal. Gonski 2.0 (DET, 2018) acknowledged that this should include identifying and cultivating potential principal candidates, supporting new principals to succeed and ongoing professional leadership development for principals. A more systematic process of preparation would have agreed to ways for identifying existing capabilities of candidates and their potential to develop further skills needed to meet the demands of the role.

\section{Key features of effective leadership development}

The extent of reform in relation to leadership development will depend on the extent to which approaches are responsive to prepare leaders for now and into the future.

The challenges facing principals and school leaders are dynamic, so the task for systems is to develop leaders who can manage school improvement and student achievement in a constantly changing and uncertain environment (Jensen et al. 2017, p. 1).

Bentley and Cazaly (2015) have claimed that the priority for the decade ahead is to "learn how to use collaboration systematically to accelerate improvement in outcomes across diverse, flexible education systems" (p. 3). Furthermore, AITSL's CEO, Mark Grant (2019) noted that an effective leadership development strategy in Australia should be focused on increasing the diversity of future leaders for all leadership roles, in all geographical locations, from rural and remote to metropolitan. Therefore, how might we best identify and accelerate leadership development for the leaders we 
require and, what are the features of a leadership development program that might address these challenges? This section outlines key elements of an effective approach to leadership development.

\section{Differentiated to meet the needs of the learner and their context}

Leadership development that is differentiated, contextual, challenges assumptions and is embedded in practice is well supported in the literature of effective adult learning and teacher professional development (Drago-Severson, 2016; Timperley, 2008). A differentiated approach to leadership development that meets the needs of the learner and the context acknowledges that adults have varying ways of knowing and accordingly interpret and make sense of experiences differently. In other words, what might feel like a 'good fit' for one may be challenging for another (DragoSeverson, 2016). Such programs should prepare leaders to analyse the situations they face, to understand how to approach various situations and decisions, and to articulate the 'why' that underpins their actions and decision making (Cunningham et al., 2019). These programs need to ensure they meet learners with different ways of knowing where they are (i.e. in a psychological sense) and then offering developmental supports and challenges to meet the needs of the learner and their context.

\section{Develops a leader's capacity to tackle adaptive challenges}

Leadership development needs to focus on growing internal capabilities as well as technical skills, to tackle adaptive challenges. Understandably, politicians and policymakers' favour quick, technical fixes, as do many school leaders. Thus, "reminding us why it would be especially helpful to fortify leaders to discern the technical and adaptive nature of challenges, thereby avoiding the pitfalls of misdiagnosing the problem and choosing a less optimal approach" (Drago-Severson \& MaslinOstrowski, 2018, p. 35).

There is a call for a more proactive, cohesive, holistic approach to leadership development. These programs should include 'technically oriented subject matter', 'continuous, customized professional learning opportunities' and 'more adaptively oriented preparation that supports authentic adult learning and internal capacity building' (Drago-Severson \& Maslin-Ostrowski, 2018; Jensen et al., 2015). Programs need to support leaders to:

develop qualities that help them to encourage and consider diverse views; share leadership responsibilities to suit specific situations; to have an outward, questioning perspective; and to constantly assess and re-align the organisation and its goals as the environment changes (Jensen et al., 2015, p. 32).

\section{Focuses on informational and transformational learning}

Developing the requisite knowledge and skills for effective educational leadership requires two types of learning: (a) informational and (b) transformational learning (Mezirow, 2000). Informational learning (acquiring facts, knowledge, and skills) is undoubtedly important, and transformational learning increases our cognitive, emotional, interpersonal, and intrapersonal capacities to manage the complexities of life (Drago-Severson, 2016; Kegan \& Lahey, 2016). Drago-Severson and MaslinOstrowski (2018) suggest that "both informational and transformational [learning], offers principals a possible pathway to grow capacity and surmount pressing challenges" (p. 35). 
Informational learning helps us to address technical problems, and transformational learning helps us to be better equipped to manage the adaptive ones. Kegan (1994) notes that transformational learning occurs when individuals develop the ability to step back and reflect, and this happens when someone changes not just the way they behave or not just the way they feel, but the way they know.

Scharmer (2019) refers to informational and transformational learning as the work of the head and heart. He suggests learners and change-makers need to cultivate different ways of knowing and that the learning process should include both to facilitate deeper learning. Scharmer (2019) notes that "while action learning shifts the outer place of learning from the classroom to the real world, wholeperson learning shifts the inner place of learning from the head to the heart, and from the heart to the head" (p. 5).

Drago-Severson (2016) suggests that designing learning experiences that help adults to understand, identify and grow their ways of knowing is one promising way to improve schools and school systems together. And that "while attention is given to building organizational capacity, we must also help principals and teachers grow their capacities for the relational, reflective, cognitive, and emotional dimensions of leadership development" (Drago-Severson \& Maslin-Ostrowski, 2018, p. 9). This learning is helpful for adaptive leadership which Heifetz, Linsky and Grashow (2009) referred to as the ability to move from the dance floor, to 'get on the balcony' above the dance floor to gain distanced perspective to see what is really happening.

\subsection{Questions framing the MSLFP}

Part One of this report has focused on the context of school leadership and has set the scene for a case for reimagining school leadership development in Australia. The information presented points to the following questions that frame the Menzies School Leader Fellowship Program (MSLFP):

- What is regarded as effective school leadership as it relates to the current context?

- Given the complex context, how might current and potential leaders be identified and supported?

- Given supply and demand issues, how can the collective be utilised to accelerate the development of 'effective leaders'? 


\section{Part 2. The Menzies Foundation fellowship}

In light of the context of leadership reviewed in Part One, Part Two of this paper proposes a new approach to leadership development. This section provides an overview of the Menzies Foundation Fellowship and a case for reimagining school leadership development with a focus on enhancing collective efficacy. School leadership is a complicated, crowded space with multiple stakeholders, and is an area in which it can be challenging to have an impact. Working with existing school leaders to better understand what influences them and what they need is a starting point. As such, the Menzies Foundation has developed a grant-based 'Incubator' approach that supports individuals who have the potential to create and implement leadership initiatives which will impact the students in their schools, and whose examples can be leveraged across the system.

The Incubator aims to generate insights and solutions to address the question:

How might we build a pipeline of school leaders equipped to lead collective efficacy in the complex school environment?

The overall purpose is:

To improve outcomes for Australian students by building a pipeline of talented school leaders who are equipped to lead well in complex school settings.

The Menzies Foundation aspires to create a platform and evidence base to support school leaders and the education system to improve student learning outcomes, through building and supporting a cross-sector collaboration to:

- identify high potential school leaders,

- develop a leadership program which contextualises school leadership in the complexity of the current system, and

- share insights to build a greater understanding of the school leader talent pipeline and leadership development interventions that best support the development of school leadership across the system.

\subsection{Overview of the Menzies School Leader Fellowship Program}

The Menzies School Leader Fellowship Program (MSLFP) is an innovative two-year leadership development program. In May 2019 the first cohort of five Fellows commenced with the second cohort scheduled to start in late-2020. Through the successive Fellowship cohorts, the Incubator approach aims to test emerging ideas about what it might take to build a pipeline of school leaders equipped to lead well in the complex school environment. 


\section{The intentions of the incubator}

The vision of the Incubator is a model of change that brings together multi-sectoral experts to experiment with complex leadership challenges and incubate new insights and solutions to these challenges. The aim is not to scale up the program, but to demonstrate a focus and model for future training of school leaders and generate ideas that may be useful to educators, policymakers and changemakers, and to support the bridging of new research, theory and practice.

\section{The fellowship}

At the centre of the Incubator is the Fellowship, which is a two-year leadership development program. The Incubator's emerging leadership development model is based on the premise that the complexity of school leadership requires a pipeline of effective leaders who move beyond a traditional-style leadership approach and towards an adaptive leadership approach. This approach is one in which school leaders act with insight and understanding of themselves (individual leadership), actively seek to influence the collective efficacy of their teaching teams (school leadership), and take a system view of the environment that affects their school and self (system leadership).

The Fellowship is focused on individual and collective development strategies to support leaders to work on themselves as adaptive leaders. This draws on psychological theory about the required levels of wellbeing and resilience needed to do this work. It is based on the premise that it is difficult to do the work necessary on self, school and system without the leader having sufficient levels of levels of wellbeing, management skills and social sensitivities as a starting point.

The Fellowship consists of five key components, outlined in Figure 1. These components include a diagnostic approach, an accelerated planning day, peer support groups, individual leadership coaching and workshop modules. 


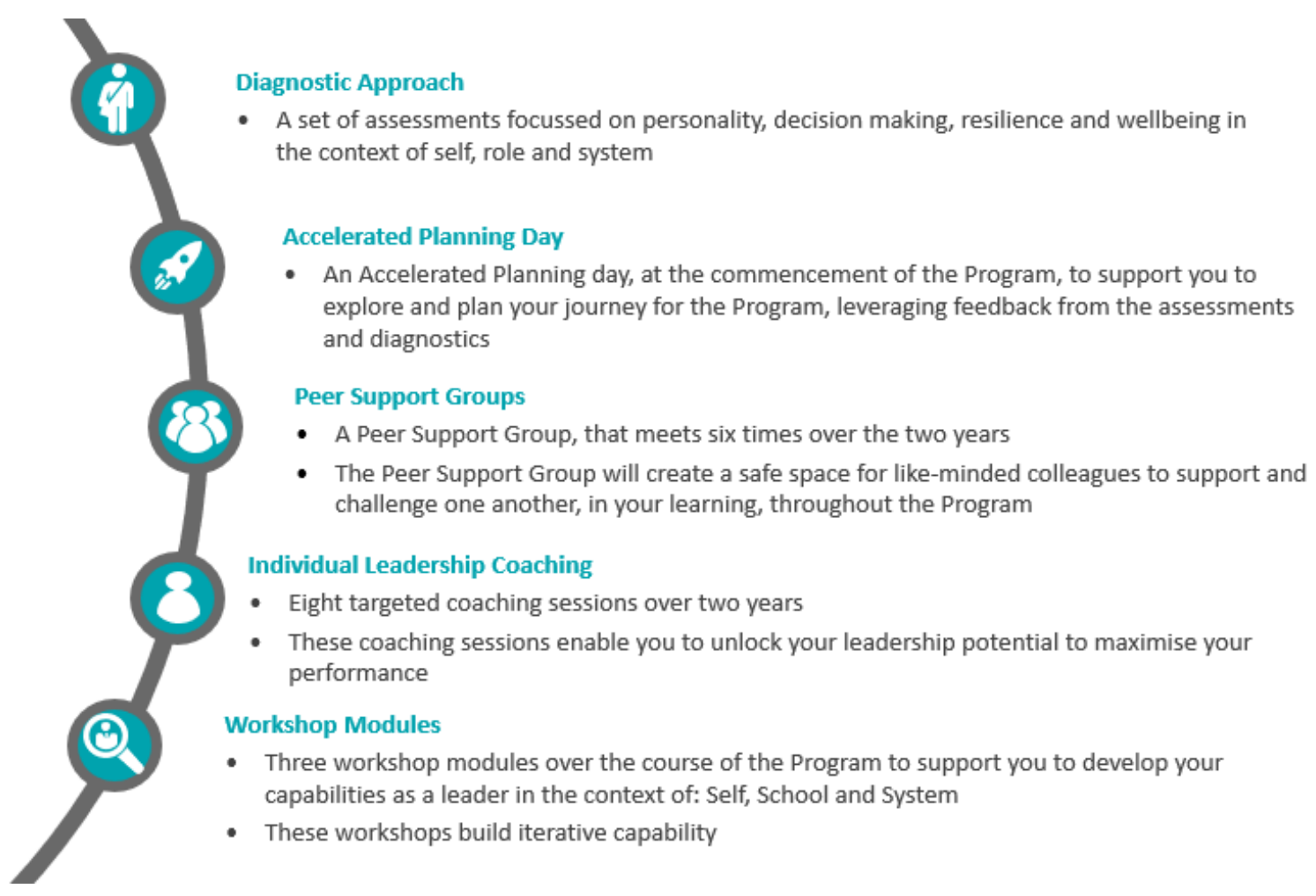

Figure 1. Five key components of the fellowship

Unlike other leadership development programs, the MSLFP was designed to address the key features of a new approach to leadership development, building on ideas outlined in Part One of this paper. This approach is elaborated in the next section.

\subsection{Distinguishing features of the MSLFP}

A recent critique of leadership preparation indicates that many programs still focus on learning about leadership rather than acquiring skills in actually doing it (Cunningham et al., 2019). This may be because historically in leadership development, "emotion, cognition, and motivation were considered separate and oppositional processes [however] now it is clear that they, in fact, work together in complex, inseparable ways" (Timperley et al. 2020, p. 47). While leadership programs have increasingly incorporated the leadership of teaching, learning, and school improvement into their design, they often miss the development of internal capabilities and the skills required to become 'learning leaders' (Lui \& Hallinger, 2018). Lui and Hallinger (2018) suggested that programs should aim to develop learning leaders and should embed four core elements:

- Inspiring leaders so that they believe they can make a difference.

- Supporting leaders to develop time management skills so that they focus on the 'right things'.

- Supporting leaders to be successful as instructional leaders, to draw on a knowledge base that includes powerful models of teaching for active learning, learner-centred assessment, and coaching teachers for success.

- Supporting leaders to develop relational skills to create productive environments for teacher learning. 
The MSLFP is unique among other leadership professional learning offerings. It addresses some key elements that are missing in other leadership programs. Specifically, the Fellowship is focused on developing internal capabilities of leaders to manage complex challenges, harnessing the power of the collective, and building an incubator focused on developing collective efficacy.

\section{Developing internal capabilities to manage complex challenges}

The Fellowship is focused on informational and transformational learning that supports leaders to build their internal capabilities to manage complex challenges. This supports leaders to gain perspective and agency across the broader system. Systems leadership brings the perspective of, and agency for, leaders in the broader system. The complexity of school leadership requires leadership development beyond traditional individual approaches and towards a systems-leadership approach.

Hallinger et al.'s (2018) study suggest that leadership development programs should seek to surface the assumptions and beliefs of prospective and practicing leaders, and cause them to challenge the limits of what they may believe is possible for them to accomplish (Lucas, 2003; Versland, 2009). Broadening and deepening the learning process through addressing the needs of the leader and their context, acknowledges that societal and personal transformation are not separate (Scharmer, 2019). The Fellowship aims to support a development process in ways that are intentional, systemic, personal and practical through needs-based coaching and action learning. This learning is embedded in the Fellows' contexts and focuses on challenges that have presented themselves in their leadership. The development of internal capabilities to manage complex challenges in the Program includes: modules to support the development of the collective; funding to support the development of each Fellow based on their diagnostics and their school context; and, support and guidance from a leadership coach.

\section{Harnessing the power of the collective}

Effective leadership development programs recognise that reform is not dependent on an individual and that building capacity in leaders to better utilise the expertise of the collective is crucial. However, "educators and leaders of all kinds are often thrust into collaborative scenarios with little instruction or training in how to do it, do it well, or in ways that are developmentally inclusive" (Drago-Severson, 2016, p. 79).

Professional learning reforms sometimes neglect to consider important steps needed to maximise the chances of success (Albers \& Pattuwage, 2017; Sharples, Albers \& Fraser, 2019). People experience collaborative situations differently (Drago-Severson \& Blum-DeStefano, 2018; Kegan \& Lahey, 2009; 2016), and often overlooked in the planning and implementation of professional learning is the increased emotion associated with new learning for teachers and leaders. These emotions create uncertainty and vulnerability, which "shows up as an unwelcomed and troublesome guest for leaders to deal with" (Timperley et al., 2020, p. 45). Therefore, developing strategies and tools that help leaders harness the collective power of the team should be a key focus of any leadership development program.

Scharmer $(2019 ; 2020)$ emphasises the importance of collaboration to meet the challenges we face in current society. He suggests that the capacity to lead transformative change requires: selfawareness, both individually and collectively; accessing curiosity, compassion, and courage; 
deepening the space for listening and conversation, and reshaping the organisation. He proposes that learning and leadership structures require reshaping in ways that deepen and broaden the focus of learning and move from the training of individuals to developing an 'eco-system of learning' (see Figure 2).

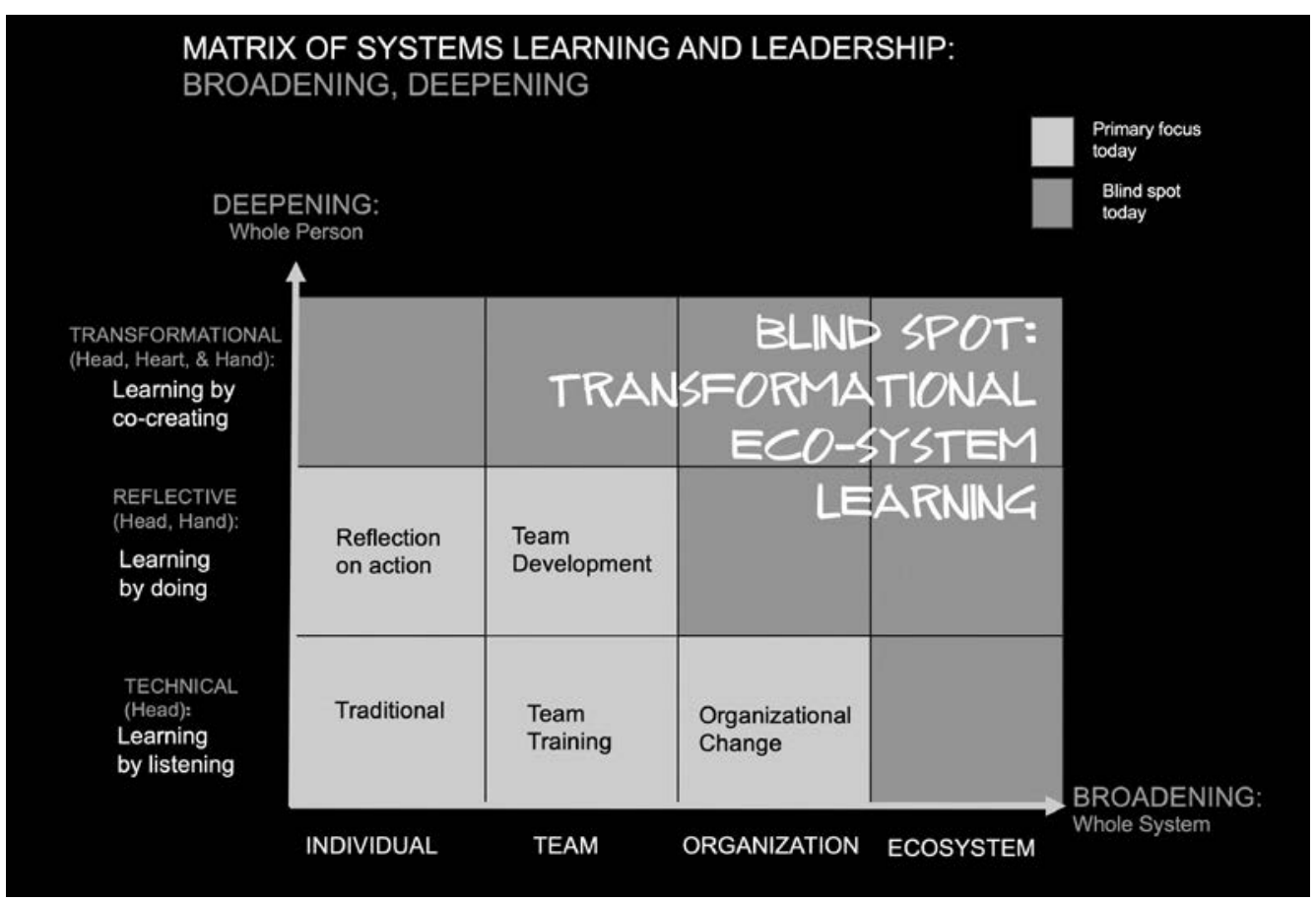

Figure 2. Matrix of systems learning and leadership (Scharmer, 2019)

The MSLFP works to shift awareness from 'ego-system' to 'eco-system' by increasing an individual's complexity of thinking to nurture deeper evaluative thinking about collective efficacy. Following Scharmer's (2019) notion of systems learning and leadership, greater self-awareness is developed through listening and perspective-taking, building capacity in others, and learning by doing the work collectively. This aligns the connection between head and heart, focusing on interpersonal and technical skills.

\section{An incubator embedded in a collective efficacy strategy}

The MSLFP provides the opportunity for Fellows to develop their leadership capabilities through the development and implementation of a 'collective efficacy' strategy within their school. This learning 'sandpit' ensures the Fellows have a context in which to practice their developing leadership skills within the collective efficacy strategy they have created with their school teams. A key difference between the coaching applied in the Fellowship, and typical educational coaching is that the Fellowship explicitly focuses on increasing collective teacher efficacy. With an increasing evidence base for the positive power of collective professional commitment and action in schools (Duignan, 2020), the Incubator model offers the opportunity for leaders to trial strategies and approaches with their school-based teams focused on enhancing collective efficacy. Fellows are provided with funds through the Fellowship to support their interventions. Although each strategy varies, the Incubator is convened around this mutual focus on collective efficacy. 
As noted earlier, the MSFLP Incubator aims to determine how might we build a pipeline of school leaders equipped to lead collective efficacy in the complex school environment? Given the attention to collective efficacy in the MSLFP, the next section focuses on defining collective teacher efficacy and examining its inclusion in this initiative as a leadership strategy to support school improvement.

\subsection{Defining collective efficacy}

There is a long tradition of research supporting the impact of beliefs and expectations on human behaviour (Bandura, 1986). Early research on teacher self-efficacy, or a teacher's belief in her/his ability to positively impact learners, has demonstrated the power of teacher expectations (Rosenthal \& Jacobson, 1968; Hallinger et al., 2018). Bandura introduced the concept of collective (teacher) efficacy in the 1990s. The concept stemmed from his earlier work on self-efficacy which was defined as "people's judgements of their capabilities to organise and execute courses of action required to attain designated types of performance" (Bandura, 1986, p. 391). Thus, efficacy beliefs refer to both the affirmation of one's capability and the strength of that affirmation as applied to a particular action or skill (Bandura, 1997). This section presents ideas related to how collective efficacy is defined and how it can influence people's behaviour and actions.

\section{Social cognitive theory}

Collective efficacy is an extension of the construct of self-efficacy and is located within the broader framework of social cognitive theory (Bandura, 1986). Social cognitive theory assumes people are influenced by personal, environmental and behavioural factors and emphasises that behaviours, beliefs and conditions influence perceptions and expectations. This theory suggests that individuals exercise control over their behaviour and that this behaviour not only influences the environment they are in, but it also affects their cognitive, emotional, and biological state (Maddux \& Gosselin, 2012).

Social cognitive theory is based on the premise that behaviour functions within a triadic reciprocal relationship involving personal, behavioural and environmental factors (see Figure 3). As a result, people learn via a combination of observing others, making sense of what they see, and reacting to conditions within their environment. Self-regulation, self-motivation, and self-efficacy are all individual-level constructs associated with social cognitive theory. 


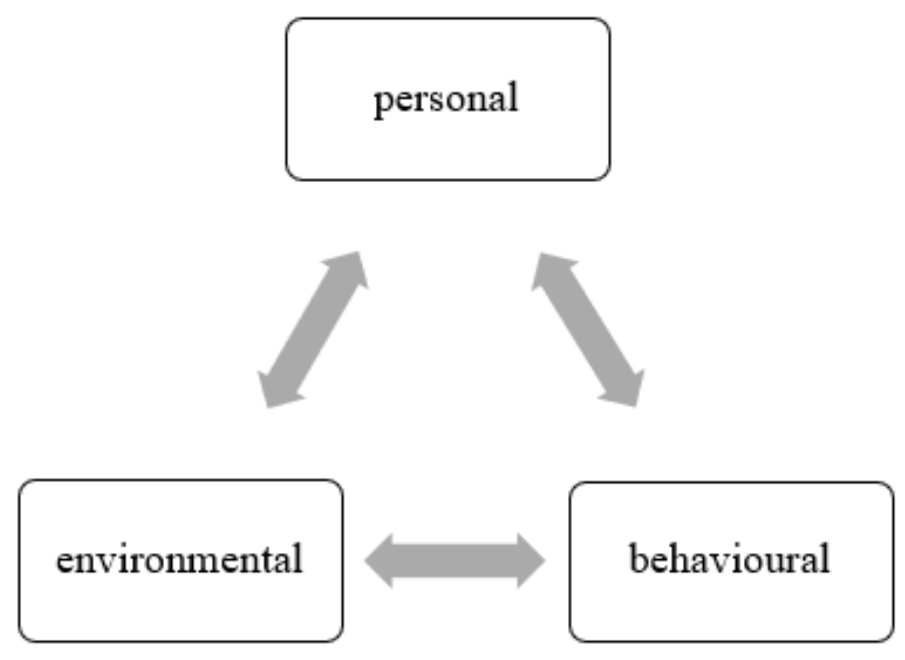

Figure 3. The triadic interplay in social cognitive theory (Bandura, 1986)

Bandura observed within this triad that a group's confidence in its abilities seemed to be associated with greater success. When a team of individuals shared the belief that through their efforts, they could overcome challenges and produce intended results, the group was more effective. He named this pattern in group dynamics collective efficacy. Collective efficacy, therefore, involves the extent to which people believe they can work together effectively to accomplish shared goals. Thus, the strength of groups and organisations lies in their sense of collective efficacy.

\section{Effects of efficacy beliefs}

Efficacy effects motivation, learning, self-regulation and achievement. According to Bandura (2012), efficacy influences choices, courses of action, effort, perseverance and resilience. Linked to efficacy is one's sense of agency which controls how decisions are made and one's ability to enact behaviours, thus affecting what one may say and do. A sense of efficacy influences the goals people choose, the level of effort they execute, how they persist with challenges, tackle tough problems and overcome setbacks. (Bandura, 1986, 1989, 2012; Geijsel, Sleegers, Stoel, \& Kruger, 2009; TschannenMoran \& McMaster, 2009; Schunk \& DiBenedetto, 2016).

The higher the sense of self-efficacy, the more likely a person is to work harder to learn a new skill and persist with their efforts, feeling more confident in their abilities to achieve and succeed even when facing difficulties. These beliefs influence how capable individuals feel about their ability to accomplish tasks and/or achieve goals. Through his research, Bandura $(2000 ; 2012)$ noted that perceived collective efficacy influenced what people choose to do as a group (priorities), how much (focused) effort they put into it, and their staying power (resilience) when group efforts failed to produce results.

\section{Sources of efficacy beliefs}

There are four main commonly accepted sources of efficacy beliefs; mastery experiences, vicarious experiences, social persuasion and physiological states (Bandura, 1986; 1989; 2012). Mastery sources relate to past personal, authentic experiences, suggesting that the experience of success can 
lead to greater efficacy. Vicarious experiences refer to the observation of others' behaviours. Witnessing others engage in challenging tasks with success may promote greater self-efficacy, providing evidence that if the person being observed has success, then maybe the observer can also experience success. Social persuasion is another source of efficacy. This includes judgments and feedback from others which play an important role in the development of an individual's self-beliefs (Zeldin \& Pajarer, 1997). Finally, physiological states include the influence of feelings which arise as a result of one's perceived effectiveness (Lumpe, Vaughn, Henrikson, \& Bishop, 2014). These four sources of efficacy beliefs influence collective efficacy. As a group experience success, success is modelled, encouragement and feedback are provided, and the group's collective efficacy and belief that they can make a difference improves (Bandura, 1997). Therefore, collective efficacy is situated and shaped by interactions with others in the environment in which they work, the evidence of impact on the collective and the collective beliefs that grow out of these interactions (TschannenMoran, Salloum \& Goddard, 2014).

\section{Insights from other fields}

Collective efficacy is a psychological construct that has been applied across a range of fields in the social sciences. Used to study social interactions of teams it has been examined in community health, sports teams and work teams, as a property of any size group, ranging from small groups to nation-states. For example, studies have found that: communities who shared the belief that they could intervene to prevent crime actually had lower rates of crime (Sampson, Raudenbush, \& Earls, 1997); teams who held positive beliefs about their team's capabilities experienced greater success; and in schools, when educators believed in their combined ability to influence student outcomes, they had significantly higher levels of achievement (Bandura, 1993; Donohoo, Hattie \& Eells, 2018).

\subsection{Collective efficacy in education}

Goddard, Hoy and Hoy (2000) defined collective teacher efficacy as:

the perceptions of teachers in a school that the efforts of the faculty as a whole will have a positive effect on students ... [and] shared beliefs that they can work together to produce effects ( $p .480)$.

Research has confirmed that collective teacher efficacy has a powerful influence on student achievement (Donohoo, 2017a; Eells, 2011; Goddard et al., 2000; Hattie, 2015; Muijs \& Reynolds, 2002; Ross \& Bruce, 2007; Sharratt \& Planche, 2016). Studies have shown a connection to efficacy and student achievement through its influence on teacher performance (Bandura, 1993; Goddard, Hoy, \& Woolfolk, 2000; Goddard \& Goddard, 2001; Ross \& Gray, 2004, 2006). Studies have also shown that having strong beliefs about collective capabilities increased achievement (Bandura 1997), explained school level differences (Goddard, Hoy \& Hoy 2000), predicted group success (Goddard \& Salloum, 2011), improved instruction (Tschannen-Moran, Salloum \& Goddard, 2015), directed professional training (Donohoo, 2017b), and affected student outcomes (Eells, 2011; Hattie, 2009). 
Teachers with a strong sense of collective efficacy are more likely to develop shared understandings and collective responsibility (Hattie, 2015; Walstrom \& Louis, 2008). They are more likely to have positive attitudes towards professional learning (Donohoo et al., 2018) and believe that they can foster learning for all students (Bandura,1993). Teachers who believe they can teach all students are more likely to exhibit teaching behaviours that support this belief. Goddard et al. (2000) acknowledged that "it is not enough to hire and retain the brightest teachers - they must also believe they can successfully meet the challenges of the task at hand" (p. 503). Thus "given the link between collective efficacy and student achievement, understanding collective efficacy in and of itself is a worthy endeavour" (Berebitsky \& Salloum, 2017, p. 2).

\section{Attributes of highly efficacious schools}

Collective efficacy helps sustain a culture of professional collaboration and continuous professional learning in a school and vice versa. Teachers who believe that they can collectively improve student learning are more likely to place greater value on collaboration. These teachers are more likely to persevere and overcome challenges and see each other as valuable resources of knowledge and learning, which itself helps to influence collective efficacy (Fullan \& Hargreaves, 2016).

Studies have found that collective efficacy is strengthened under certain conditions, and there are specific actions that school leaders can take to improve collective efficacy among teachers. Schools with a high sense of collective efficacy:

- Focus on the right work to develop a guaranteed and viable curriculum to ensure students have access to the same essential knowledge and skills regardless of the teacher to whom they are assigned (DuFour, 2011).

- Use evidence of student learning to discuss, evaluate, plan and improve instruction (Hattie, 2009).

- Build their instructional knowledge and skills (Ross \& Gray, 2006).

- Create opportunities for teachers to share skills and experiences (Ross \& Gray, 2006).

- Provide actionable feedback on performance and involve teachers in school decision making (Ross \& Gray, 2006).

\section{Conditions that foster collective efficacy}

A number of researchers have examined conditions that foster collective efficacy in schools. Donohoo (2017a), for example, offers a synthesised list of six enabling conditions for fostering collective efficacy in schools. These enabling conditions, outlined in Figure 4, include advanced teacher influence, goal consensus, teachers' knowledge about one another's work, cohesive staff, the responsiveness of leadership, and effectiveness of the intervention. 


\section{Advanced Teacher Influence}

Advanced teacher influence is defined by the degree to which teachers are provided opportunities to participate in important school-wide decisions.

2. Goal Consensus

Reaching consensus on goals not only increases collective efficacy. It also has a direct and measurable impact on student achievement.

3. Teachers' Knowledge About One Another's Work

Teachers gain confidence in their peers' ability to impact student learning when they have more intimate knowledge about each other's practice.

4. Cohesive Staff

Cohesion is defined as the degree to which teachers agree with each other on fundamental educational issues.

\section{Responsiveness of Leadership}

Responsive leaders show concern and respect for their staff and protect teachers from issues that detract from their teaching time and focus.

6. Effective Systems of Intervention

Effective systems of intervention help in ensuring that all students are successful.

Figure 4. Six enabling conditions for fostering collective efficacy (Donohoo, 2017a)

Elliott (2019) found that effective school leaders are explicit about the focus on improvement and impact and share common narratives about high expectations, inviting teachers to choose their own effective teaching methods to accomplish this. She suggests these leaders establish feedback mechanisms to facilitate higher impact and position teachers as professional agents, such that a focus on improving impact on students becomes the norm in the school, building a narrative that 'this is how we do it here' (Elliott, 2019).

Hattie and Zierer's (2018) research found that in schools where a shared sense of collective efficacy is present, their culture reflects beliefs in high expectations for student success. The perceptions that reflect the actions of educators in these schools included, 'we are evaluators', 'we are change agents', and 'we collaborate'. The attributes of highly efficacious schools where that teachers believed their task was to evaluate the effect of their practice on student process and achievement. These teachers valued working together to improve and believed that success and failure in student learning were more about what they did or did not do (Hattie \& Zierer, 2018).

\section{Collective efficacy beliefs support collaboration and teacher development}

There is a wealth of research highlighting the importance of professional collaboration as a potential catalyst for changing teachers' practice for the better (Harris \& Jones, 2019; Hattie, 2009; Timperley, 2008). Fullan and Hargreaves (2016) note that Hattie's research (2009) highlighted that professional collaboration is one of the best investments a system can make provided it is well-led, wellsupported, and included quality content. 
Collective efficacy beliefs support collaboration and teacher development. Berebitsky and Salloum's (2017) study found a significant relationship between a school's collective efficacy level and teachers' instructional practices. They concluded that turning to colleagues for instructional advice that is focused on the impact of their teaching on learning enhanced teachers' collective efficacy. Similarly, Siciliano (2016) reported that peer relationships influenced teachers' efficacy perceptions. They observed that teachers who had confidence in their colleagues' abilities turned to them for advice. Prelli (2016) found that a collaborative environment increased a teacher's chance to share their teaching experiences and to get feedback from colleagues. Goddard et al. (2015) reported:

Moreover, when teacher collaboration is centred on instructional improvement in schools, it is more likely to build real capability and hence enhance the resolve of teachers that they possess the ability necessary to achieve student learning goals (p. 504).

\section{Construct confusion}

Efficacy involves more than thinking positively or being optimistic. It is not a generalised trait, but rather it encompasses a diverse set of movable beliefs, tied to action and agency, which constitutes the ability to make things happen (Bandura, 2012). The belief that all students can learn and that educators can influence their learning has a powerful impact on student outcomes. However, using the term 'efficacy' can be misleading if 'teacher efficacy' is conflated with 'teacher effectiveness' or 'successful teaching'. Goddard, Hoy and Woolfolk (2004) recommend it is important to avoid the term 'teacher efficacy', and to talk instead about teachers' perceptions of efficacy, efficacy judgments, a sense of efficacy, perceived efficacy, or efficacy beliefs.

The term collective efficacy is a construct and, as such, is made up of many parts. Consequently, collective efficacy has often been misinterpreted and simplified when applied to practice, and is commonly used as a proxy for terms such as 'collaboration'. Even though collaboration is vital to developing collective efficacy, and collective efficacy implies that teachers who work together and believe they can make a difference will improve student outcomes, it is actually more complicated than that. Hattie (2017) explains that the collective belief of teachers about their ability to promote successful student outcomes in their schools needs to be reinforced by evidence that they actually have a collective impact. He added that it is these beliefs that can transpire into actions, given the right conditions. As such, school leaders have a major role in ensuring that the right conditions are in place and "that there is evidence of appropriately challenging standards of progress shared by all who work in the school" (Hattie, 2016, p. 10-11). 


\subsection{Collective efficacy as a leadership focus}

The importance of collective efficacy is identified in the research literature. The next section articulates the rationale for focusing on collective efficacy in the MSLFP.

\section{The link between instructional leadership and collective efficacy}

If a leader could promote higher levels of collective efficacy within the school or within teams, collective teachers' efficacy could be a means to improve student performance (Prelli, 2016, p. 176).

Given the importance of instructional leadership in enhancing student learning outcomes, and the importance of collective efficacy, a focus on collective efficacy in leadership development is essential. Instructional leadership practices have the potential to shape collective efficacy. Studies have found that effective leaders support school improvement in ways that positively influence teachers' collective efficacy beliefs, including through promoting a culture of collaboration around instructional practice (Leithwood, Louis, Anderson \& Wahlstrom, 2004; Leithwood \& Mascall, 2008; Lui \& Hallinger, 2018).

Instructional leadership has been positively associated with both collective teacher efficacy and teacher commitment, both of which have been associated with school quality and school improvement (Goddard et al., 2000, 2004; Hoy et al., 2002; Leithwood \& Jantzi, 2008; Leithwood et al., 2010). Goddard et al.'s (2015) study confirmed that principals' instructional leadership is a significant positive predictor of collective efficacy beliefs through its influence on teachers' collaborative work. He concluded that "a consistent emphasis on instructional leadership can support teachers' collaborative work to improve instruction, which in turn supports collective efficacy beliefs and group success" (Goddard et al., 2015, p. 506).

\section{Developing collective efficacy is an adaptive challenge}

The research literature suggests there are several conditions that foster collective efficacy in schools; however, enhancing collective efficacy is not a simple endeavour. As emphasised by Donohoo (2017a), although school characteristics associated with collective efficacy increase the likelihood that collective efficacy will develop, they do not cause it to happen. The success of collective efficacy lies in the critical nature of collaboration (Donohoo et al., 2018), and there is often variability in the strength of collaboration. Hattie (2015) clarified that collaboration to improve collective efficacy needs to include a focus on the evidence of impact, common understandings of what impact means, ways to know about the magnitude of the effect of teaching, and how the impact is shared across many groups of students. Once this is established, he suggests, "the focus should shift to the nuances, the mediators and the incremental changes needed to adopt and implement these methods that maximize impact in each context" (Hattie, 2015, p. 24).

Enhancing collective efficacy, therefore, becomes an adaptive challenge. This adaptive challenge is focused on understanding and addressing the elements that nurture collective efficacy (such as effective communication, empathy, active listening and being open to trying new ideas) and those that undermine it (such as an inability to communicate, time constraints, reluctance to change). 
Leaders engaged in this work need to focus on developing the relational trust among their teachers and acquiring the skills to address issues in a way that is respectful to the feelings and viewpoints of others (Donohoo et al., 2018). This includes modelling social sensitivities by paying close attention to verbal and nonverbal clues and exercising situational awareness and being aware of when tensions rise, and undercurrents exist that have the potential to derail joint problem-solving (Marzano, Waters, \& McNulty, 2005). An adaptive challenge requires rethinking leadership to ensure it focuses on collaboration, as too often attempts will fail when there is little attention on how the collaboration is working.

Duignan (2020) noted that:

based on a widespread review of recent national and international reports there appears to be a view that we need to fundamentally rethink and redesign school leadership to be more inclusive, collaborative and distributed, especially if the desire is to build world-class communities of learners ( $p .65$ ).

Fullan (2010) furthermore claimed that:

the missing link for system and school leadership is the powerhouse force of collective capacity building and efficacy [and] there is no force so durable and potent as a social force ... gale-force commitment occurs because peers commit to peers, and hierarchies become flatlined in their interactions (p. 102).

Thus, an important question to address is "how can leaders help create and nurture school cultures that value collective responsibility for quality learning and enhance the collective efficacy of teachers?" (Duignan, 2020, p. 67).

\section{Collective efficacy emphasises the implicit and explicit conditions of system change}

It has long been recognised that values, beliefs and assumptions need to be articulated and explored as an integral part of any reform process and that shifts in system conditions are more likely to be sustained when working at three levels of change: explicit, semi-explicit and implicit. Kania, Kramer and Senge (2018) explained that while there are conditions that hold problems in place, less explicit conditions have a huge impact on shifting systems. They note that "systems change can increase their odds for success by focusing on less explicit but more powerful conditions for change" (Kania, et al., 2018, p. 7). Therefore, leaders need to pay sufficient attention to the relationships, power dynamics and underlying mental models (i.e. biases, tacit assumptions) that are embedded into the systems in which they work. Figure 5 shows six interdependent conditions that typically play significant roles in holding a social or environmental problem in place and requires both structural and transformative changes. Reported by Kania et al. (2018), these conditions exist with varying degrees of visibility to individuals in the system, largely due to how explicit, or tangible, they are made to most people. 


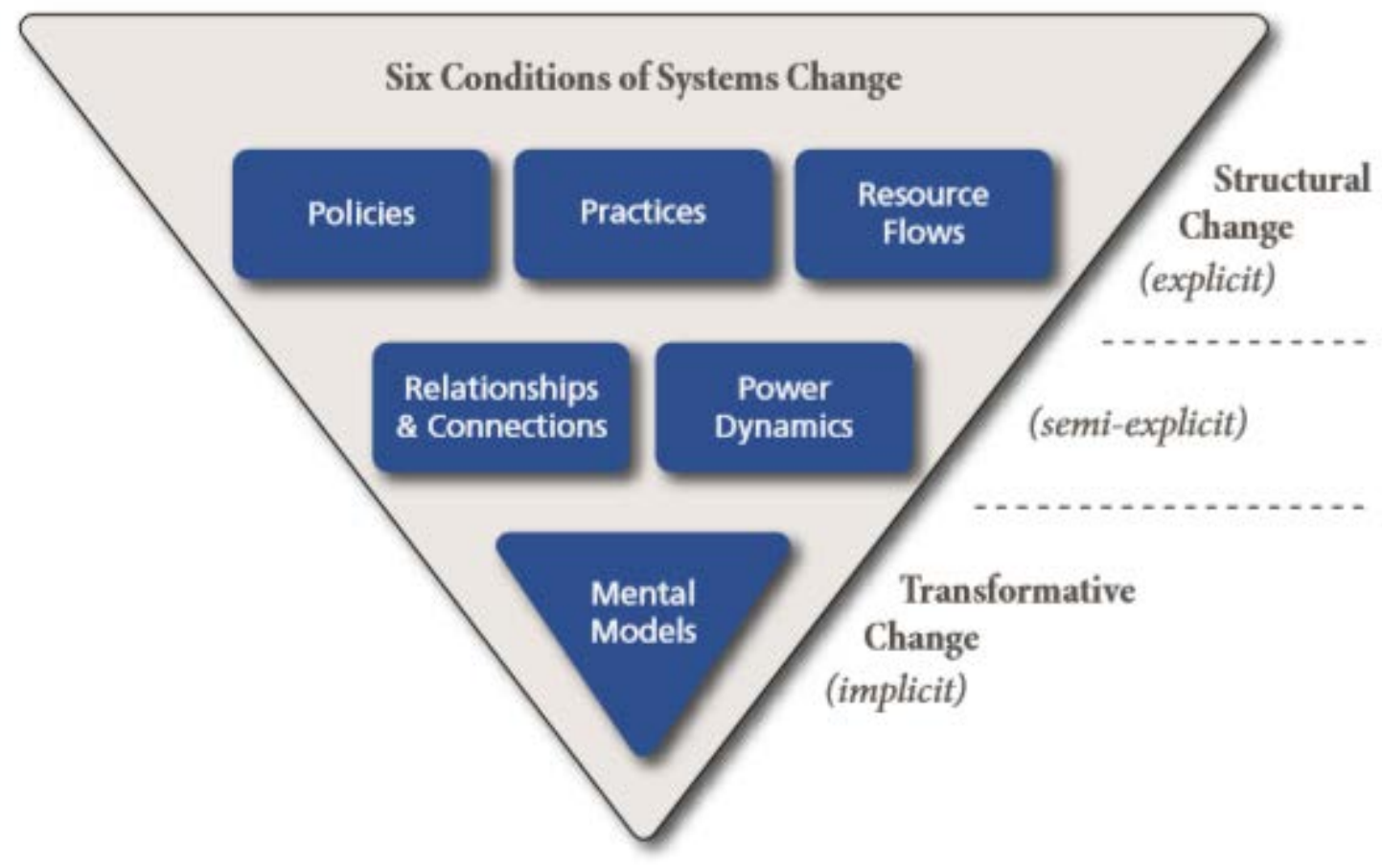

Figure 5. Six conditions of systems change (Kania et al., 2018, p. 4)

A focus on enhancing collective efficacy emphasises both implicit and explicit conditions of systems change. Scharmer (2018) notes that it is the less visible stuff, such as the quality of relationships, the patterns of thinking, conversing, the subtle qualities of deep listening and organising that give rise to collective behaviour which in turn produce practical results.

Duignan (2020) suggests that:

changing structures, roles, processes, or simply distributing leadership tasks and responsibilities among key stakeholders are desirable, but it will not ensure that a collective sense of responsibility for quality learning and learning outcomes follows; motivating forces much deeper than these are required (p.67).

Collective efficacy is dependent on relationships and shared responsibility for the quality of their school's learning and learning outcomes. Thus, developing collective efficacy emphasises a focus on both the implicit and explicit conditions of system change.

\section{Educators with a strong sense of collective efficacy are more likely to persevere}

With the job of teaching becoming increasingly demanding; developing collective efficacy that helps teachers feel more powerful rather than powerless to make a difference is vital in an increasingly VUCA world. Collective teacher efficacy not only predicts student academic achievement (Bandura, 1993, Goddard et al., 2000) but where strong collective efficacy exists teachers and leaders are better able to reduce inequity by closing achievement gaps (Goddard, Skrla \& Salloum, 2017). Collective teacher efficacy is also a strong predictor of commitment and persistence and therefore schools with a strong sense of collective efficacy are more likely to persist in the face of adversity. 


\subsection{Areas where further research is warranted}

The importance of collective teacher efficacy is acknowledged in the literature, and consequently, it has become more prominent in education policies. Although there is literature to support the justification for a focus on collective efficacy as a leadership focus within the MSLFP, there are areas which require further examination in the research literature. Areas, where further investigation is warranted, is outlined in this section.

The first area for further investigation proposes that unless the right conditions are put in place by school leaders at all levels, collective teacher efficacy will remain a catchphrase. This area of research suggests there is a lack of ability in translating findings into practice and thus "effective preparation must be offered for aspiring and current leaders in schools to develop the socialemotional skills to create these antecedents for a deep and transformative form of collective teacher efficacy" (Loughland \& Ryan, 2020, p. 9).

Secondly, further research is required to examine what is known about the relationships between leadership and collective efficacy. In particular, there is a gap in the literature about what is known about the relationship between collective efficacy and leadership styles and practices (Donohoo, 2018). Furthermore, given Leithwood et al.'s (2020) recognition of generic attributes of school leaders, it would be useful to identify the traits needed for collective efficacy. Duignan (2020) suggests that an important research question is "how can leaders help create and nurture school cultures that value collective responsibility for quality learning and enhance the collective efficacy of teachers?" (p. 67).

Finally, Goddard et al. (2015) propose that how leaders and teachers work together to improve instruction and collective efficacy beliefs deserves more attention. They found that strong instructional leadership is essential to put in place the structures and processes that support teachers' collaborative instructional improvement. However, further, identification was required of approaches leaders might take to support teachers' collaborative work and make normative changes in their schools that could improve student outcomes.

\subsection{Collective efficacy in the MSLFP}

Collective efficacy in the MSLFP involves inspiring leaders to believe that together with their colleagues, they can make a difference to the learning lives of students. The development of leadership in the MSLFP effects instructional leadership and collective teacher efficacy. It suggests that if there is a focus on informational and personal and professional transformational learning, embedded in a strategy to enhance collective efficacy (beliefs and practices), then (alterable) influential leadership skills will improve (the ability to communicate effectively, make decisions) ensuring a greater capacity to manage the complex school environment. It is anticipated that through participating in the MSLFP, a leader's confidence, capability and time management will improve, and this will impact their wellbeing and their complexity of thinking. This, in turn, will accelerate the development of their instructional leadership practice leading to enhanced collective teacher efficacy and student outcomes. 
Recognising the importance of collective efficacy as a key leadership strategy, the MSLFP provides a platform to develop, support and evaluate collective efficacy through project-based interventions and from learning insights from the Fellowship. This section describes the development, support and evaluation of collective efficacy as a key leadership strategy within the MSLFP.

\section{Developing collective efficacy}

Goss (2017) suggested it is worthwhile to consider collective efficacy as a systemic as well as a school attribute. The work of system leadership in the MSLFP suggests that if leaders see a collective responsibility for system change, separately and together, they can change the system. Thus, the development of collective efficacy in the MSLFP is supported by a co-design approach to build agency and develop insight from each Fellow's school team, the peer support groups which offer a community of practice for the Fellows, and the Collaboration Team who oversee the research, design and evaluation of the MSLFP (see Figure 6).

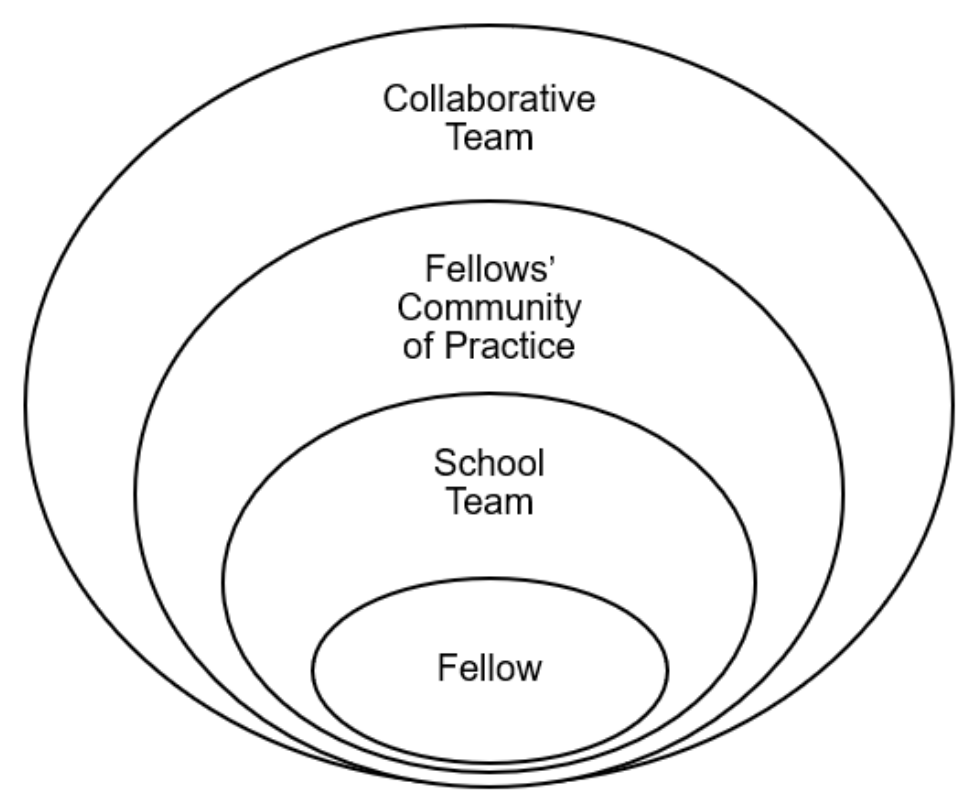

Figure 6. The MSLFP incubator focused on developing collective efficacy

The Incubator is the container in which experiments are designed, and learnings synthesized within the MSLFP. This involves action learners and action researchers coming from a range of sectors to bring their experiences to share, reflect, co-sense and co-create learnings and insights.

\section{Supporting collective efficacy}

The Incubator's working theory of change at the school level is that: if adequately "equipped" leaders co-design and implement a collective efficacy strategy in their schools, then mindsets, relationships and capabilities needed for collective efficacy will improve across the school teaching team, which means the teaching team will be more confident, collaborative and effective, which in turn will lead to improved student outcomes (see Figure 7). 


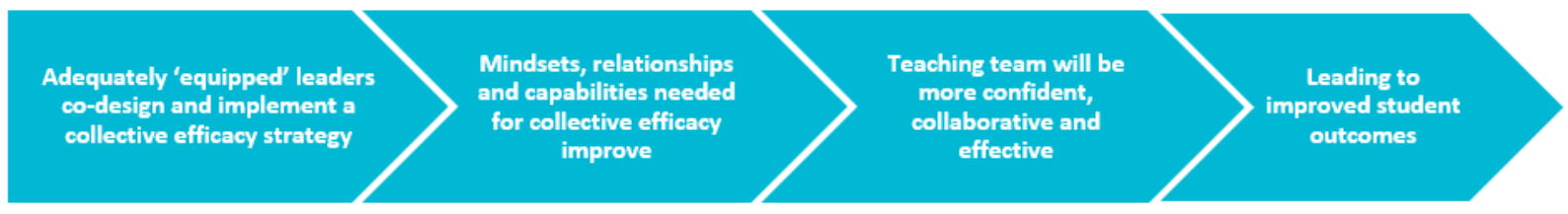

Figure 7. The incubator's working theory of change

This work combines the "adaptive" learning required for building collective efficacy in a school with the "technical" work of a school. In practice, this means strategies could focus on the ways of working, mindsets, relationships, leadership, and/or capabilities needed to improve collective efficacy.

Customised needs-based school projects support the development of collective efficacy in the MSLFP. Fellows have access to funds to support their school-based implementation and to develop insights. The MSLFP works to support Fellows to become more aware of their own behaviour and its impact on the collective and to connect more consciously and intentionally to develop new patterns of collaboration and strengthen collective efficacy in their schools. The 'working outside-in' approach (Heifetz \& Dorffer, 2018) asks leaders to examine: challenges being faced in developing collective efficacy; particular personal difficulties in practicing leadership; specific behaviours required to lead collective efficacy in their context; and, what can be done to mobilise greater adaptive success.

\section{Evaluating collective efficacy}

Collective teacher efficacy is commonly measured through self-report Likert scale surveys such as those created by Goddard et al. (2000) and Tschannen-Moran and Barr (2004). Both have been validated as reliable instruments and require participants to indicate their strength in perception against items which refer to the capacity and capability of faculty members, students and the school. Namely, they try to measure the confidence towards the probability, feasibility or likelihood of executing a given behaviour. Others (e.g. Donohoo, 2017a, Donohoo, O'Leary \& Hattie, 2020), have developed reliable questionnaires for examining enabling conditions for collective efficacy.

Victorian Government schools have access to a version of Goddard's (2002) collective efficacy tool through the Staff Opinion Survey. The staff opinion survey is conducted annually, it provides a measurement of collective efficacy in the school, and will form the base of evaluating collective efficacy in the MSLFP. Alongside this, other instruments for evaluating collective efficacy will be used.

Although there are several collective efficacy scales available, Abedini, Bagheri and Sadighi (2018) suggest that new methods for evaluating collective efficacy are required, for "most have tried to measure the construct in a decontextualized way. In fact, they do not succeed in capturing the contextual specificity of the construct, which is highly recommended" (Tschannen- Moran et al., 1998, p. 202). To accompany the collective teacher efficacy survey (Goddard, 2002), a Menzies Collective Efficacy Progress Mapping Tool has been developed and will form the basis of evaluating collective efficacy and developing insights within the MSLFP. 


\section{The collective efficacy progress mapping tool}

The Menzies Collective Efficacy Progress Mapping Tool is a diagnostic tool for school leaders and their teams to support the diagnosis, intervention, implementation and evaluation of collective efficacy in their school. This progress mapping tool was developed to mobilise teams to consider and value multiple perspectives and types of evidence that would support a holistic collective efficacy diagnosis. The mapping tool is used by a school leadership team to assess, track and improve collective efficacy across the school. It enables leaders and teachers to come to a shared, high-level view of their progress in leading a whole-of-school change process. Specifically, the tool allows school leaders and teachers to map what progress they have already made, what they are working on now, and what they will work on next.

The mapping tool facilitates an assessment of a school's collective efficacy within four areas and across four phases of maturity. The four key areas are:

- School. The extent to which there is a shared commitment to achieving positive learning outcomes for students.

- Leaders. The extent of confidence that teachers have in school leaders that the school will achieve its goals.

- Teachers. The extent of confidence that teachers have in their ability to collectively achieve these goals.

- Students. The extent to which students believe that educators in the school believe students can achieve their goals.

Each phase of maturity includes indicators to support schools in making their diagnosis. During the process of diagnosis, the school team draw on evidence to support their decision making against each indicator within the phases of development:

- Phase 1: Recognising the possibility for change.

- Phase 2: Building foundations for strong collective efficacy.

- Phase 3: Collective efficacy is strengthening.

- Phase 4: A high sense of collective efficacy with demonstrable impact on achieving positive learning outcomes.

The development of the tool was informed by the research literature, and the tool will be further developed and refined during the Menzies Incubator process. As part of the MSLFP research and evaluation, resources will be developed to accompany the Menzies Collective Efficacy Progress Mapping tool to support diagnosis, interventions, implementation and evaluation. This will include, surveys and assessments to support diagnosis, aligned to each area, and links to practical resources generated by the Incubator, aligned to each phase. 


\subsection{Conclusion and a future research agenda}

More and more, education systems are turning to school leadership to drive improvement in the quality of teaching and learning. For leaders to play this role, there is a need to work together to support the development of all leaders. Policymakers', system leaders', and school leaders' efforts toward successful education reforms might be "better served by strategically and intentionally considering how to foster collective efficacy throughout the conceptualization, design, delivery, and assessment of change initiatives" (Donohoo, 2018, p. 323). The research reviewed here suggests that a more systematic approach to supporting school leaders is required, that enhances collective efficacy to meet the complex challenges schools face.

While acknowledging that there are a number of leadership initiatives in the education sector, there is a general consensus that leadership development requires further consideration. This paper suggests that the education system needs a talent pipeline of school leaders that are better prepared for the complex role of leading the school improvement required to lift student performance. And, if we can talent spot leaders earlier, provide them with aspirational, accelerated pathways, and focus on developing instructional leaders with collective responsibility for system change, then student outcomes will be enhanced, and systems will improve.

School leaders are fundamental to a high-quality education system and to achieving the vision for all young Australians to be confident and creative individuals, successful lifelong learners, and active and informed members of the community. However, the role of school leaders is becoming increasingly complex and demands an orientation of continuous learning and the necessary skill set to meet these challenges.

This review has suggested that existing leadership development offerings are not sufficient to equip current or future school leaders for the complexity of their roles, particularly with the adaptive challenges they face. It suggests that leadership programs which support leaders to develop and nurture collective efficacy are critical for improving student outcomes in schools. The MSLFP considers how we might build a pipeline of school leaders equipped to lead collective efficacy in the complex school environment. The research and evaluation questions to be addressed through the MSLFP are:

- What conditions are needed to improve the leadership of collective efficacy in schools? What practices and interventions enable these conditions to improve?

- How might we foster collective efficacy throughout the conceptualization, design, delivery, and assessment of change initiatives?

- What leadership styles and practices foster collective beliefs that leverage measurable impacts on student learning outcomes?

- What have we learned about the wider system affecting the pipeline of school leadership in Australia for developing collective efficacy? Does a focus and developing skills in collective efficacy more likely lead more to become leaders?

- What do we know about current school leaders and the capabilities that are required to build collective efficacy leadership within their schools? Based on the skill required, how might we better identify, support and accelerate the development of future school leaders? 


\section{References}

Abedini, F., Bagheri, M., \& Sadighi, F. (2018). Exploring Iranian collective teacher efficacy beliefs in different ELT settings through developing a context-specific English language teacher collective efficacy scale, Cogent Education, 5(1). https://doi.org/10.1080/2331186X.2018.1552340

Ainley, J., \& Gebhardt, E. (2013). Measure for measure. A review of outcomes of school education in Australia. Australian Council of Educational Research. https://research.acer.edu.au/cgi/viewcontent.cgi?article=1015\&context=ar_misc

Albers, B., \& Pattuwage, L. (2017). Implementation in Education: Findings from a Scoping Review. Evidence for Learning. https://evidenceforlearning.org.au/evidence-informededucators/implementation-in-education/

Alice Springs (Mparntwe) Education Declaration. (2019). Education Council. https://docs.education.gov.au/system/files/doc/other/final_-_alice_springs_declaration__17_february_2020_security_removed.pdf

Australian Institute for Teaching and School Leadership. AITSL. (2011). Australian Professional Standard for Principals. Australia, AITSL.

Australian Institute for Teaching and School Leadership. AITSL. (2015). Preparing future leaders. Effective preparation for aspiring school principals. https://www.aitsl.edu.au/docs/defaultsource/general/preparing-future-leaders.pdf

Australian Institute for Teaching and School Leadership. AITSL. (2017). Leading for impact: Australian guidelines for school leadership development. AITSL. https://www.aitsl.edu.au/docs/defaultsource/national-policy-framework/leading-for-imapct-australian-guidelines-for-schoolleadership-development.pdf

Australian Student Wellbeing Framework. (2018). Education Services Australia. https://studentwellbeinghub.edu.au/educators/framework

Bandura, A. (1977). Self-efficacy: Toward a unifying theory of behavioural change. Psychological Review, 84, 191-215. https://doi.org/10.1037/0033-295X.84.2.191

Bandura, A. (1986). Social foundations of thought and action. A social cognitive theory. Prentice-Hall.

Bandura, A. (1993). Perceived self-efficacy in cognitive development and functioning. Educational Psychology, 28(2), 117-148. https://doi.org/10.1207/s15326985ep2802_3

Bandura, A. (1997). Self-efficacy: The exercise of control. Freeman.

Bandura, A. (2006). Towards a psychology of human agency. Perspectives on Psychological Science, 1(2), 164-180. https://doi.org/10.1111/j.1745-6916.2006.00011.x

Bandura, A. (2012). On the functional properties of perceived self-efficacy revisited. Journal of Management, 38(1), 9-44. https://doi.org/ 10.1177/0149206311410606 
Barber, M., \& Moushed, M. (2007). How the world's best-performing school systems come out on top. http://www.mckinsey.com/industries/social-sector/our-insights/how-the-worlds-bestperforming-school-systems-come-out-on-top

Bennis, W. G., \& Thomas, R. J. (2002, September). Crucibles of leadership. Harvard Business Review, $80(9), 39-45$.

Bentley, T., \& Cazaly, C. (2015). The shared work of learning: lifting educational achievement through collaboration. An agenda for systemic change. Centre for Strategic Education (CSE). http://www.cse.edu.au/zfiles/SemPaper247Sample.pdf

Berebitsky, D., \& Salloum, S. J. (2017). The relationship between collective efficacy and teachers' social networks in urban middle schools. AERA Open, 3(4).

http://doi.org/10.1177/2332858417743927

Bryk, A., Gomez, L. M., Grunow, A., \& LeMahahieu, P. G. (2015). Learning to improve: How America's schools can get better at getting better. Harvard Education Press.

Cahill, H., Beadle, S., Farrelly, A., Forster, R., \& Smith, K. (2014). Building resilience in children and young people: A literature review. Victoria DET.

https://www.education.vic.gov.au/Documents/about/department/resiliencelitreview.pdf

Care, E., Kim, H., Anderson, K., \& Gustafsson-Wright, E. (2017). Skills for a changing world: national perspectives and the global movement. Centre for Universal Education at Brookings. https://www.brookings.edu/wp-content/uploads/2017/03/global-20170324-skills-for-achanging-world.pdf

Cunningham, K., VanGronigen, B., Tucker, P., \& Young, M. (2019). Using powerful learning experiences to prepare school leaders. Journal of Research on Leadership Education, 14(1), 74 97. https://doi.org/10.1177/1942775118819672

Daggett, B. (2014). Addressing current and future challenges in education: Lessons learned from the nation's most rapidly improving and transformative schools. International Centre for Leadership in Education. http://leadered.net/pdf/2014MSC_AddressingCurrentandFutureChallenges.pdf

Day, C. (2017). School leadership as an influence on teacher quality. In X. Zhu, A. Goodwin, \& H. Zhang (Eds.), Quality of teacher education and learning (pp. 101-118). Springer.

Department of Education and Training. DET. (2018). Through growth to achievement: The report of the review to achieve educational excellence in Australian schools. Australian Government DET. https://docs.education.gov.au/system/files/doc/other/662684_tgta_accessible_final_0.pdf

Dimmock, C., \& Hattie, J. (1996). School principals' self-efficacy and its measurement in a context of restructuring. School Effectiveness and School Improvement, 7(1), 62-75.

https://doi.org/10.1080/0924345960070103 
Dinham, S. (2007). How schools get moving and keep improving: Leadership for teacher learning, student success and school renewal. Australian Journal of Education, 51(3), 263-275. https://doi.org/10.1177/000494410705100304

Dinham, S. (2013). Connecting clinical teaching practice with instructional leadership. Australian Journal of Education, 57(3), 225-236. https://doi.org/10.1177/0004944113495503

Dinham, S., Elliott, K., Rennie, L., \& Stokes, H. (2018). 'I'm the principal'. Principal learning, action, influence and identity. ACER Press.

Donohoo, J. (2017a). Collective efficacy: How educators' beliefs impact student learning. Corwin Press.

Donohoo, J. (2017b). Collective teacher efficacy research: Implications for professional learning. Journal of Professional Capital and Community, 2(2), 101-116. https://doi.org/10.1108/JPCC-102016-0027

Donohoo, J. (2018). Collective teacher efficacy research: Productive patterns of behaviour and other positive consequences. Journal of Educational Change, 19(3), pp. 323 345.https://doi.org/10.1007/s10833-018-9319-2

Donohoo, J., Hattie, J., \& Eells, R. (2018). The power of collective efficacy. Educational Leadership, 75(6), 40-44.

Donohoo, J., O'Leary, T., \& Hattie, J. (2020). The design and validation of the enabling conditions for collective teacher efficacy scale (EC-CTES). Journal of Professional Capital and Community, 5(2), 147166. https://doi.org/10.1108/JPCC-08-2019-0020

Drago-Severson, E. (2009). Leading adult learning: Supporting adult development in our schools. Corwin/Sage and Learning Forward.

Drago-Severson, E. (2016). Teaching, learning, and leading in today's complex world: Reaching new heights with a developmental approach. International Journal of Leadership in Education, 19(1), 56-86. https://doi.org/10.1080/13603124.2015.1096075

Drago-Severson, E., \& Blum-DeStefano, J. (2018). Leading change together. Developing educator capacity within schools and systems. ASCD.

Drago-Severson, E., \& Maslin-Ostrowski, P. (2018). In translation: School leaders learning in and from leadership practice while confronting pressing policy challenges. Teachers College Record, 120, p. $1-44$.

DuFour, R. (2011). Work together, but only if you want to: We cannot waste another quarter-century inviting or encouraging educators to collaborate. Kappan Magazine, 92(5), 57-61. https://doi.org/10.1177/003172171109200513

Duignan, P. (2012). Educational leadership: Together creating ethical learning environments. Cambridge University Press. 
Duignan, P. (2020). Leading educational systems and schools in times of disruption and exponential change: A call for courage, commitment and collaboration. Emerald Publishing.

Edwards-Groves, C. E., Grootenboer, P., Hardy, I., \& Rönnerman, K. (2018). Driving change from 'the middle': middle leading for site-based educational development. School Leadership \& Management, 39(3-4), 315-333. https://doi.org/10.1080/13632434.2018.1525700

Eells, R. (2011). A meta-analysis of the relationship between collective teacher efficacy and student achievement. (PhD thesis, Loyola University). https://ecommons.luc.edu/cgi/viewcontent.cgi?article=1132\&context=luc_diss

Elliott, K. (2015). Teacher performance appraisal: More about performance or development? Australian Journal of Teacher Education, 40(9), 102-116. https://doi.org/10.14221/ajte.2015v40n9.6

Elliott, K. (2019). Teachers' perceptions and experiences of a performance and development process as a mechanism to support teacher development. (PhD thesis, The University of Melbourne). https://minerva-access.unimelb.edu.au/handle/11343/228901

Elmore, R. (2007). Educational improvement in Victoria. Victoria DET. https://pdfs.semanticscholar.org/2b92/2803c07490d5480fed6a6b27f992ee6f1b22.pdf

Foundation for Young Australians (2018). The new work reality. https://www.fya.org.au/wpcontent/uploads/2018/06/FYA_TheNewWorkReality_sml.pdf

Freeman, C., O'Malley, K., \& Eveleigh, F. (2014). Australian teachers and the learning environment. An analysis of teacher response to TALIS 2013. Final report. Australian Council of Educational Research. https://research.acer.edu.au/cgi/viewcontent.cgi?article=1001\&context=talis

Fullan, M. (2010). All systems go: The change imperative for whole system reform. Corwin Press.

Fullan, M., \& Hargreaves, A. (2016). Bringing the profession back in: Call to action. Learning Forward. https://michaelfullan.ca/wp-

content/uploads/2017/11/16_BringingProfessionFullanHargreaves2016.pdf

Geijsel, F. P., Sleegers, P., Stoel, R., \& Kruger, M. (2009). The effect of teacher psychological and school organisational and leadership factors on teacher's professional learning in Dutch schools. Elementary School Journal, 109(4), 406-427. https://doi.org/10.1086/593940

Gillard, J. (2019, February 18). Building a mentally healthy generation. Teacher. Australian Council of Educational Research. https://www.teachermagazine.com.au/columnists/julia-gillard/buildinga-mentally-healthy-generation.

Goddard, R., Hoy, W. K., \& Hoy, A. W. (2000). Collective teacher efficacy: Its meaning, measure and impact on student achievement. American Educational Research Journal, 37(2), 479-507. https://doi.org/10.2307/1163531 
Goddard, R. D., \& Goddard, Y. L. (2001). A multilevel analysis of teacher and collective efficacy in urban schools. Teaching and Teacher Education, 17(7), 807-818.

https://doi.org/10.1016/S0742-051X(01)00032-4

Goddard, R. (2002). A theoretical and empirical analysis of the measurement of collective efficacy: The development of a short form. Educational and Psychological Measurement, 62(1), 97-110. https://doi.org/10.1177/0013164402062001007

Goddard, R. D., Hoy, W. K., \& Woolfolk Hoy, A. (2004). Collective efficacy beliefs: Theoretical developments, empirical evidence, and future directions. Educational Researcher, 33(3), 3-13. https://doi.org/10.3102/0013189X033003003

Goddard, R. D., \& Skrla, L. (2006). The influence of school social composition on teachers' collective efficacy beliefs. Educational Administration Quarterly, 42(2), 216-235. https://doi.org/10.1177/0013161X05285984

Goddard, R. D., \& Salloum, S. J. (2011). Collective efficacy beliefs, organisational excellence, and Leadership. In K. S. Cameron \& G. Spreitzer (Eds.), Oxford Handbook for Positive Organizational Scholarship (p. 642-650). Oxford University Press. https://doi.org/10.1093/oxfordhb/9780199734610.013.0048

Goddard, R., Goddard, Y., Kim, E., \& Miller, R. (2015). A theoretical and empirical analysis of the roles of instructional leadership, teacher collaboration, and collective efficacy beliefs in support of student learning. American Journal of Education, 121(4), $501-530$. https://doi.org/10.1086/681925

Goddard, R., Skrla, L., \& Salloum, S. (2017). The role of collective efficacy in closing student achievement gaps: A mixed methods study of school leadership for excellence and equity. Journal of Education for Students Placed at Risk (JESPAR), 22(4), 220-236. https://doi.org/10.1080/10824669.2017.1348900

Gomendio, M. (2017). Empowering and enabling teachers to improve equity and outcomes for all, International Summit on the Teaching Profession. OECD Publishing. https://doi.org/10.1787/9789264273238-en

Goss, P. (2019, November 11). Reading progress is falling between year 5 and 7, especially for advantaged students: 5 charts. The Conversation. https://theconversation.com/readingprogress-is-falling-between-year-5-and-7-especially-for-advantaged-students-5-charts-124634

Goss, P. (2017). Towards an adaptive education system in Australia. Grattan Institute. https://grattan.edu.au/wp-content/uploads/2017/11/894-Adaptive-Education.pdf

Graham, L., Berman, J., \& Bellert, A. (2015). Sustainable learning: inclusive practices for 21st century classrooms. Cambridge University Press.

Grant, M. (2019, September 18). Diversity the key to improvement performance in schools. Media release. https://www.aitsl.edu.au/secondary/news-and-media/media-release---diversity-thekey-to-improved-performance-in-schools 
Hallinger, P., \& Heck, R. H. (1998). Exploring the principal's contribution to school effectiveness: 1980-1995. School Effectiveness and School Improvement, 9(2), 157-191. https://doi.org/10.1080/0924345980090203

Hallinger, P. (2011). Leadership for learning: lessons from 40 years of empirical research. Journal of Educational Administration 49(2), 125-142. https://doi.org/10.1108/09578231111116699

Hallinger, P., \& Murphy, J. F. (2012). Running on empty? Finding the time and capacity to lead learning. NASSP Bulletin, 97(1), 5-21. https://doi.org/10.1177/0192636512469288

Hallinger, P., \& Wang, W. C. (2015). Assessing leadership for learning with the Principal Instructional Management Rating Scale. Springer. https://doi.org/10.1007/978-3-319-15533-3

Hallinger, P., Hosseingholizadeh, R., Hashemi, N., \& Kouhsari, M. (2018). Do beliefs make a difference? Exploring how principal self-efficacy and instructional leadership impact teacher efficacy and commitment in Iran. Educational Management Administration \& Leadership, 46(5), 800-819. https://doi.org/10.1177/1741143217700283

Hargreaves, A., Shirley, D., Wangia, S, Bacon, C., \& D’Angelo, M. (2018). Executive summary. Leading from the middle: spreading learning, well-being, and identity across Ontario. Code Consortium for System Leadership and Innovation. http://ccsli.ca/downloads/2018Leading_From_the_Middle_Summary_Final-EN.pdf

Harris, A., \& Jones, M., (2019). Leading professional learning with impact, School Leadership \& Management, 39(1), 1-4. https://doi.org/10.1080/13632434.2018.1530892

Hattie, J. (2009). Visible learning: A synthesis of over 800 meta-analyses relating to achievement. Routledge.

Hattie, J. (2015). What works best in education: The politics of collaborative expertise. Pearson. https://www.pearson.com/content/dam/corporate/global/pearson-dotcom/files/hattie/150526_ExpertiseWEB_V1.pdf

Hattie, J. (2016). Shifting away from distraction to improve Australia's schools: Time for a reboot. ACEL Monograph Series. http://www.acel.org.au/acel/ACEL_docs/Publications/Monograph/Monograph_54_2016_WEB. pdf

Hattie, J. (2017). Collaborative impact. Keynote at Cognition Education's Collaborative Impact: Research and Practice Conference. https://visible-learning.org/2017/05/video-john-hattiecollaborative-impact/

Hattie, J., \& Zierer, K. (2018). 10 mindframes for visible learning. Routledge.

Heifetz, R. (1994). Leadership without easy answers. Harvard University Press.

Heifetz, R. A., \& Linsky, M. (2002). Leadership on the line: Staying alive through the dangers of leading. Harvard Business School Press. 
Heifetz, R. A., \& Linsky, M. (2004). When leadership spells danger. Educational Leadership, 61(7), 3337.

Heifetz, R. A., Linsky, M., \& Grashow, A. (2009). The practice of adaptive leadership. Harvard Business.

Heifetz, R. A, \& Dorffer, T. (2018). Adaptive leadership as key to organisational problem-solving. http://www.doerfferleadership.com/uploads/4/2/4/4/42448421/zoe_2018_02_heifetz_doerffe r_eng.pdf

Horng, E. L., Klasik, D., \& Loeb, S. (2010). Principal's time use and school effectiveness. American Journal of Education, 116(4), 491-523. https://doi.org/10.1086/653625

Jensen, B., Hunter, A., Lambert, T., \& Clark, A. (2015). Aspiring principal preparation. https://www.aitsl.edu.au/docs/default-source/default-document-library/aspiring-principalpreparation-(print-friendly).pdf

Jensen. B., Sonnemann. J., Roberts-Hull. K., \& Hunter. A. (2016). Beyond PD: Teacher professional learning in high-performing systems. National Centre on Education and the Economy. http://www.ncee.org/wp-content/uploads/2015/08/BeyondPDWeb.pdf

Jensen, B., Downing, P., \& Clark, A. (2017). Preparing to lead: Lessons in principal development from high-performing education systems. National Centre on Education and the Economy. http://ncee.org/wp-content/uploads/2017/10/PreparingtoLeadFINAL101817.pdf

Kania, J., Kramer, M., \& Senge, P. (2018). The water of systems change. FSG. https://www.fsg.org/publications/water_of_systems_change

Kegan, R. (1994). In over our heads: The mental demands of modern life. Harvard University Press.

Kegan, R. (2000). What "form" transforms? A constructive-developmental approach to transformative learning. In J. Mezirow (Ed.), Learning as transformation: Critical perspectives on a theory in progress (pp. 35-69). Jossey-Bass.

Kegan, R., \& Lahey, L. L. (2009). Immunity to change: How to overcome it and unlock the potential in yourself and your organisation. Harvard Business Review Press.

Kegan, R., \& Lahey, L. L. (2016). An everyone culture: Becoming a deliberately developmental organisation. Harvard Business Review Press.

Lahl, S., \& Egan, T.D. (2012). Bridging the complexity gap. Leading effectively in a VUCA world. Graziadio Business Review, 15(3).

Leithwood, K., Louis, K. S., Anderson, S., \& Wahlstrom, K. (2004). Review of research: How leadership influences student learning. Wallace Foundation.

https://www.wallacefoundation.org/knowledge-center/Documents/How-LeadershipInfluences-Student-Learning.pdf 
Leithwood, K., \& Jantzi, D. (2008). Linking leadership to student learning: The contributions of leader efficacy. Educational Administration Quarterly 44(4), 496-528.

https://doi.org/10.1177/0013161X08321501

Leithwood, K., Harris, A., \& Hopkins, D. (2008). Seven strong claims about successful school leadership. School Leadership and Management, 28(1), 27-42.

https://doi.org/10.1080/13632430701800060

Leithwood, K., \& Mascall, B. (2008). Collective leadership effects on student achievement. Educational Administration Quarterly, 44(4), 529-561. https://doi.org/10.1177/0013161X08321221

Leithwood, K., Patten, S. \& Jantzi, D. (2010). Testing a conception of how school leadership influences student learning. Educational Administration Quarterly 46(5), 671-706. https://doi.org/10.1177/0013161X10377347

Leithwood, K. (2012). The Ontario leadership framework 2012 with a discussion of the research foundations. Toronto Institute for Education Leadership. https://www.education-leadershipontario.ca/application/files/2514/9452/5287/The_Ontario_Leadership_Framework_2012__with_a_Discussion_of_the_Research_Foundations.pdf

Leithwood, K., Harris, A., \& Hopkins, D. (2020). Seven strong claims about successful school leadership revisited. School Leadership and Management, 40(1), 5 - 22. https://doi.org/10.1080/13632434.2019.1596077

Loughland, T. \& Ryan, M. (2020). Beyond the measures: the antecedents of teacher collective efficacy in professional learning. Professional Development in Education. https://doi.org/10.1080/19415257.2020.1711801

Lucas. S. E. (2003). The development and impact of principal leadership self-efficacy in middle level schools: Beginning an inquiry. (PhD Thesis, University of Illinois). http://files.eric.ed.gov/fulltext/ED478737.pdf

Lucas, B., \& Smith, C. (2018). The capable country: Cultivating capabilities in Australian education. Mitchell Institute. http://www.mitchellinstitute.org.au/wp-content/uploads/2018/10/Thecapable-country.pdf

Lui, S., \& Hallinger, P. (2018). Principal instructional leadership, teacher self-efficacy, and teacher professional learning in China: Testing a mediated-effects model. Educational Administration Quarterly, 54(4), 501-528. https://doi.org/10.1177/0013161X18769048

Lumpe, A., Vaughn, A., Henrikson, R., \& Bishop, D. (2014). Teacher professional development and self-efficacy beliefs. In R. Evans, J. Luft, C. Czerniak, \& C. Pea (Eds.), The role of science teachers' beliefs in international classrooms: From teacher actions to student learning (pp. 49-63). Sense Publishers.

Maddux, J. E., \& Gosselin, J.T. (2012). Self-efficacy. In: M.R. Leary and J.P. Tangney (Eds.), Handbook of self and identity. ( $3^{\text {rd }}$ ed.). (p.198-224). The Guildford Press. 
Marshall, K. (1996). How I confronted HSPS (hyperactive superficial principal syndrome) and began to deal with the heart of the matter. Phi Delta Kappan, 77(5), 336-345.

Marzano, R., Waters, T., \& McNulty, B. (2005). School leadership that works. ASCD.

Masters, G. (2019). Nurturing wonder and igniting passion: Designs for a future school curriculum. NSW Curriculum Review Interim Report. NSW Education Standards Authority. https://nswcurriculumreview.nesa.nsw.edu.au/pdfs/interimreport/chapters/NSW-CurriculumReview-Interim-Report.pdf

McCallum, F., Price, D., Graham, A., \& Morrison, A. (2017). Teacher wellbeing: A review of the literature. Association of Independent Schools NSW.

https://www.aisnsw.edu.au/Resources/WAL\%204\%20[Open\%20Access]/Teacher\%20Wellbeing \%20A\%20Review\%20of\%20The\%20Literature\%20Faye\%20McCallum\%202017.pdf

Melbourne Declaration on Educational Goals for Young Australians. (2008). Ministerial Council on Education, Employment, Training and Youth Affairs.

http://www.curriculum.edu.au/verve/_resources/National_Declaration_on_the_Educational_G oals_for_Young_Australians.pdf

Mezirow, J. (2000). Learning to think like an adult: Core concepts of transformation theory. In J. Mezirow \& Associates (Eds.), Learning as transformation (pp. 3-33). Jossey-Bass.

Miller, M. S. (2015). High school principals and self-efficacy: A phenomenological examination into the belief in ability to perform the principalship. (PhD Thesis, Illinois State University). https://ir.library.illinoisstate.edu/etd/318

Mogato, A. (2019, October 28). The connection between student wellbeing and outcomes. The Educator K/12. https://www.theeducatoronline.com/k12/news/the-connection-betweenstudent-wellbeing-and-outcomes/267628

Muijs, D., \& Reynolds, D. (2002). Teacher beliefs and behaviour: What really matters? Journal of Classroom Interaction, 37(2), 3-13. https://www.jstor.org/stable/23870407

Mumford, M. D., Watts, L. L., \& Partlow, P. J. (2015). Leader cognition: Approaches and findings. Leadership Quarterly, 26(3), 301-306. https://doi.org/10.1016/j.leaqua.2015.03.005

Munby, S. (2019). Imperfect leadership. Crown House Publishing.

NSW Department of Education. (2017). Principal workload and time use study. Deloitte. https://education.nsw.gov.au/content/dam/main-education/gef/media/documents/Principalworkload-and-time-use-study-Nov-2017.pdf

Oades, L. (2018). How do we learn to thrive? The emergence of wellbeing science [Video]. The University of Melbourne. https://www.youtube.com/watch?v=ocqFzGjMDa4

O'Connor, M., Cloney, D., Kvalsvig, A., \& Goldfeld, S. (2019). Positive mental health and academic achievement in elementary school: new evidence from a matching analysis. Educational Researcher, 48(4), 205-216. https://doi.org/10.3102/0013189X19848724 
Ontario Leadership Framework. (2013). Institute for Education Leadership. https://www.educationleadershipontario.ca/application/files/8814/9452/4183/Ontario_Leadership_Framework_OLF.pdf

Organisation for Economic Cooperation and Development. OECD. (2019). TALIS 2018 results (Volume 1): Teachers and school leaders as lifelong learners. OECD Publishing. https://doi.org/10.1787/1d0bc92a-en

Organisation for Economic Cooperation and Development. OECD. (2018). Trends shaping education Spotlight 14. http://www.oecd.org/education/ceri/Spotlight-14-Good-Vibrations-Students'Well-being.pdf

Prelli, G. E. (2016). How school leaders might promote higher levels of collective teacher efficacy at the level of school and team. English Language Teaching, 9(3), 174-180. https://doi.org/10.5539/elt.v9n3p174

Riley, P. (2019). The Australian principal occupational health, safety and wellbeing survey: 2018 data. https://www.principalhealth.org/au/2018_AU_Final_Report.pdf

Robinson, V., Lloyd, C., \& Rowe, K. (2008). The impact of leadership on student outcomes: An analysis of the differential effects of leadership types. Educational Administration Quarterly, 44(5), 635-674. https://doi.org/10.1177/0013161X08321509

Robinson, V., Hohepa, M., \& Lloyd, C. (2009). School leadership and student outcomes: Identifying what works and why - Best evidence synthesis iteration [BES]. New Zealand Ministry of Education. https://www.educationcounts.govt.nz/_data/assets/pdf_file/0015/60180/BESLeadershipWeb-updated-foreword-2015.pdf

Robinson, V. (2017, August 28). Capabilities required for leading improvement: Challenges for researchers and developers [Paper presentation]. Research Conference 2017 - Leadership for Improving Learning - Insights from Research.

https://research.acer.edu.au/research_conference/RC2017/28august/2

Rosenthal, R., \& Jacobson, L. (1968). Pygmalion in the classroom. The Urban Review 3(1), 16-20. https://doi.org/10.1007/BF02322211

Ross, J., \& Bruce, C. (2007). Professional development effects on teacher efficacy: Results of the randomised field trial. Journal of Educational Research, 101(1), 50-59. https://doi.org/10.3200/JOER.101.1.50-60

Ross, J. A., Hogaboam-Gray., A., \& Gray, P. (2004). Prior student achievement, collaborative school processes, and collective teacher efficacy. Leadership and Policy in Schools, 3(3), 163-188. https://doi.org/10.1080/15700760490503689

Ross, J. A., \& Gray, P. (2006). Transformational leadership and teacher commitment to organisational values: The mediating effects of collective teacher efficacy. School Effectiveness and School Improvement, 17(2), 179-199. https://doi.org/10.1080/09243450600565795 
Sampson, R., Stephen. J, Raudenbush, W., \& Felton, E. (1997). Neighbourhoods and violent crime: A multilevel study of collective efficacy. Science, 277(5328), 918-924.

https://doi.org/10.1126/science.277.5328.918

Scharmer, O. (2018). The essentials of Theory U. Core principals and applications. Berrett-Koehler Publishers.

Scharmer, O. (2019, April 16). Vertical literacy: Reimagining the $21^{\text {st }}$-century university. Medium. https://medium.com/presencing-institute-blog/vertical-literacy-12-principles-for-reinventingthe-21st-century-university-39c2948192ee

Scharmer, O. (2020, March 17). Eight emerging lessons: From coronavirus to climate action. Medium. https://medium.com/presencing-institute-blog/eight-emerging-lessons-fromcoronavirus-to-climate-action-683c39c10e8b

Schleicher, A. (2016). Teaching excellence through professional learning and policy reform: lessons from around the world. OECD Publishing. https://doi.org/10.1787/23127090

Schleicher, A. (2018). Valuing our teachers and raising their status. International Summit on the Teaching Profession. OECD Publishing. https://doi.org/10.1787/23127090

Schunk, D.H., \& DiBenedetto, M. K. (2016). Self-efficacy theory in education. In K. R. Wentzel, \& D. B. Miele (Eds.). Handbook of Motivation at School (pp. 34-54). Routledge. https://doi.org/10.4324/9781315773384

Senge, P.M. (1990). The Fifth Discipline: The Art and Practice of the Learning Organization. Doubleday Currency.

Sharples, J., Albers, B., \& Fraser, S. (2019). Putting evidence to work - A school's guide to implementation. Education Endowment Foundation, U.K.

https://educationendowmentfoundation.org.uk/tools/guidance-reports/a-schools-guide-toimplementation/

Sharratt, L. \& Planche, B. (2016). Leading Collaborative Learning: Empowering Excellence. Corwin.

Shoho, A. R., Barnett, B. G., \& Tooms, A, K. (Eds.). (2010). The challenges for new principals in the twenty-first century: Developing leadership capabilities through professional support. Information Age.

Siciliano, M. D. (2016). It's the quality not the quantity of ties that matters: Social networks and selfefficacy beliefs. American Educational Research Journal, 53(2), 227-262. https://doi.org/10.3102/0002831216629207

Spiegel, J. S. (2012). Open-mindedness and intellectual humility. Theory and Research in Education, 10(1), 27-38. https://doi.org/10.1177/1477878512437472

Thomson, S., De Bortoli, L., \& Underwood, C. (2017). PISA 2015: Reporting Australia's results. Australian Council of Educational Research. https://research.acer.edu.au/ozpisa/22 
Thomson, S., \& Hillman, K. (2019). Australian Report. Volume 1. Teachers and school leaders as lifelong learners. Australian Council of Educational Research. https://research.acer.edu.au/talis/6

Thomson, S., De Bortoli, L., Underwood, C., \& Schmid, M. (2019). PISA 2018: Reporting Australia's Results. Volume I Student Performance. Australian Council of Educational Research. https://research.acer.edu.au/ozpisa/35

Thomson, P., Lingard, G., \& Wrigley, T. (2012). Reimagining school change: The necessity and reasons for hope. In T. Wrigley, P. Thomson, \& B. Lingard (Eds.). Changing schools: Alternative ways to make a world of difference. Sage.

Timperley, H. (2008). Teacher professional learning and development. International Bureau of Education (IBE) \& International Academy of Education. http://edu.aru.ac.th/childedu/images/PDF/benjamaporn/EdPractices_18.pdf

Timperley, H., Ell, F., Le Fevre, D., \& Twyford, K. (2020). Leading professional learning: Practical strategies for impact in schools. ACER Press.

Tschannen-Moran, M., Woolfolk Hoy, A., \& Hoy, W. K. (1998). Teacher efficacy: Its meaning and measure. Review of Educational Research, 68(2), 202-248. https://doi.org/10.3102/00346543068002202

Tschannen-Moran, M., \& Barr, M. (2004). Fostering student learning: The relationship of collective efficacy and student achievement. Leadership and Policy in Schools, 3(3), 189-209. https://doi.org/10.1080/15700760490503706

Tschannen-Moran, M., \& McMaster, P. (2009). Sources of self-efficacy: Four professional development formats and their relationship to self-efficacy and implementation of a new teaching strategy. The Elementary School Journal, 110(2), 228-245. https://doi.org/10.1086/605771

Tschannen-Moran, M., Salloum, S. \& Goddard, R. (2014). Context matters: The influence of collective beliefs and shared norms. In L. E. Martin, S. Kragler, D. J. Quatroche, \& K. L Bauserman (Eds). International Handbook of Research on Teachers' Beliefs (pp. 301-316). https://doi.org/10.4324/9780203108437

Versland, T. M. (2009). Self-efficacy development of aspiring principals in education leadership preparation programs. (PhD Thesis, Montana State University). https://scholarworks.montana.edu/xmlui/bitstream/handle/1/2476/VerslandT0509.pdf

Victorian Department of Education and Training. (2018). Principal health and wellbeing strategy 2018 - 2021. https://www.education.vic.gov.au/hrweb/Documents/PrincipalHWB-Strategy2018-2021.pdf

Walstrom, K. L., \& Louis, K. S. (2008). How teachers experience principal leadership: The roles of professional community, trust, efficacy, and shared responsibility. Education Administration Quarterly, 44(4), 458-495. https://doi.org/10.1177/0013161X08321502 
Wilson, J. (2018). The human side of changing education. How to lead change with clarity, conviction, and courage. Corwin.

World Economic Forum. (2016). The Future of Jobs: Employment, Skills and Workforce Strategy for the Fourth Industrial Revolution. http://www3.weforum.org/docs/WEF_Future_of_Jobs.pdf

World Health Organization. (2019) Burn-out an "occupational phenomenon": International Classification of Diseases. WHO. https://www.who.int/mental_health/evidence/burn-out/en

Zeldin, A. L., \& Pajarer, F. (1997). Against the odds: Self-efficacy beliefs of women with math-related careers. American Educational Research Journal, 37(1), 215-246.

https://doi.org/10.3102/00028312037001215 

